\title{
Reactivity of iron-sulfur clusters with nitric oxide
}

\author{
Erin L. Dodd, Jason C. Crack, Andrew J. Thomson and Nick E. Le Brun \\ Centre for Molecular and Structural Biochemistry, School of Chemistry, University of East \\ Anglia, Norwich Research Park, Norwich NR4 7TJ, UK
}

\section{Introduction}

\subsection{Structure and chemistry of iron-sulfur (Fe-S) clusters that function in biological sensing}

Iron-sulfur (Fe-S) clusters are cofactors in proteins that carry out a wide variety of functions including electron transfer, catalysis, the sensing of iron and of gases, including $\mathrm{O}_{2}$ and $\mathrm{NO}$, in bacterial gene regulation. In this chapter we describe recent progress from this laboratory, and others, in understanding the reactions of $\mathrm{NO}$ with a range of Fe-S proteins that underlie the sensing of the gas for transcriptional regulation [1].

Clusters with cores [2Fe-2S] and [4Fe-4S] (Figure 1) are those most commonly found in biology [2]. The [2Fe-2S] core is the simplest, consisting of a $\left[\mathrm{Fe}_{2}-\left(\mu_{2}-\mathrm{S}\right)_{2}\right]$ rhomb, each iron being coordinated by two further ligands that are normally amino acid residue side chains. This leads to tetrahedral coordination at each iron (Figure 1A). Cysteine thiolates are by far the most common amino acid ligands, but other residues such as histidine, aspartate and serine are occasionally found. The [4Fe-4S] cluster can be described as a cube with $\mathrm{Fe}$ and $S$ atoms at alternating positions at the vertices (Figure 1B). The way the cluster is coordinated by the protein clearly dictates function. In the case of gas sensing by regulation of DNA transcription, reaction of the cluster with a particular gas causes a conformational change that alters the nature of the binding and affinity for DNA (or another protein). For example, a [2Fe2S] cluster is coordinated by four residues that lie in the same plane, which is perpendicular to that of the rhomb (Figure $1 \mathrm{~A}$ ), whereas a [4Fe-4S] is coordinated by a tetrahedral array of coordinating residues. Thus cluster interconversion will entail significant spatial rearrangement of the protein cluster ligands that is capable of triggering conformational changes.

$<$ Figure 1 here $>$

The [3Fe-4S] cluster (Figure 1C) is stable in some proteins, such as hydrogenase, where it functions as part of an electron transfer chain of clusters. In other proteins it is an intermediate formed during cluster transformation from the [4Fe-4S] core to the [2Fe-2S] cluster, for example, caused by $\mathrm{O}_{2}$ as in FNR, or to complete loss of iron due to low iron concentrations in aconitase [3,4]. Other, more exotic iron-sulfur clusters, include the six cysteine-coordinated [4Fe-3S] cluster located close to the catalytic center of $\mathrm{O}_{2}$-resistant $\mathrm{NiFe}$ hydrogenases [5], and the P-cluster cluster of nitrogenase. The latter comprises two [4Fe-4S] clusters that share one sulfide, generating a [8Fe-7S] cluster [6].

The oxidation states of individual iron atoms in the [2Fe-2S], [3Fe-4S] and [4Fe-4S] clusters are invariably $\mathrm{Fe}^{2+}$ or $\mathrm{Fe}^{3+}$. The d-electrons are arranged in the high spin configurations, $S=2$ or $S=5 / 2$, respectively, because the ligand field generated by the tetrahedral coordination is too weak to force low spin configurations. Coupling between the unpaired electron spins on adjacent iron ions is usually, but not invariably, antiferromagnetic in which the lowest energy state has the spins anti-parallel to one another. This can lead to a low or zero overall cluster spin state [7]. The electronic and magnetic properties of Fe-S 
clusters are thus characteristic of cluster type. A range of biophysical techniques can be used to identify cluster type, and to follow their interconversions and reactions with gases (see Section 2).

The accessible cluster oxidations states in a protein environment invariably differ by only one electron even though more states may be attained by application of extremes of potential with, for example, electrochemical techniques. Thus, in proteins the $[2 \mathrm{Fe}-2 \mathrm{~S}]^{2+1+1+}$ and $[3 \mathrm{Fe}-4 \mathrm{~S}]^{1+/ 0}$ couples are typically in the range -100 to $-600 \mathrm{mV}$ versus SHE [2],. Exceptions do exist, for example the Rieske $[2 \mathrm{Fe}-2 \mathrm{~S}]^{2+1 /+}$ cluster, which is coordinated by two Cys and two His residues, has a much more positive potential ( $+200 \mathrm{mV}$ versus SHE)), in line with its function in the respiratory chain [8]. The [4Fe-4S] cluster can, in proteins, access one of two single electron reductions either $[4 \mathrm{Fe}-4 \mathrm{~S}]^{3+/ 2+}$ or $[4 \mathrm{Fe}-4 \mathrm{~S}]^{2+11+}$, but not both in same protein environment. For example, HiPIPs (high potential iron proteins) have reduction potentials in the range +50 to $+450 \mathrm{mV}[9]$ and cycle via $[4 \mathrm{Fe}-4 \mathrm{~S}]^{3+/ 2+}$ whereas the more commonly found couple $[4 \mathrm{Fe}-4 \mathrm{~S}]^{2+/ 1+}$ occurs at much lower potentials.

Fe-S cluster proteins originated in the seas of the ancient, anaerobic Earth where iron, as soluble $\mathrm{Fe}^{2+}$, was available along with sulfide ions $\left(\mathrm{S}^{2-}\right)[2,10]$. The appearance of $\mathrm{O}_{2}$ in the atmosphere following the evolution of photosynthetic organisms resulted in major opportunities for life (the evolution of $\mathrm{O}_{2}$-respiring organisms) but major challenges too, one of which was the inherent sensitivity of $\mathrm{Fe}-\mathrm{S}$ clusters to react with oxygen species, including $\mathrm{O}_{2}$, superoxide ions $\left(\mathrm{O}_{2}^{-\cdot}\right)$ and hydrogen peroxide $\left(\mathrm{H}_{2} \mathrm{O}_{2}\right)$. This can lead to partial or complete destruction of the cluster, with consequent loss of biological function. In some cases, the reaction is more 'controlled' leading to cluster conversion. Reactions with strongly coordinating species such as nitric oxide (NO) also typically lead to cluster damage or interconversion, and, in the case of reaction with $\mathrm{NO}$, cluster modifications are coupled to a multiplicity of redox processes (see below). The toxicity of reactive oxygen and nitrogen species in part lies in their reactivity towards Fe-S cluster proteins.

\subsection{Chemistry and biology of nitric oxide (NO)}

In higher eukaryotes NO fulfils a wide range of biological functions, as a key secondary messenger regulating vasodilation, as a neurotransmitter, as a regulator of protein activity through post-translational modification, and as a cytotoxin generated by the immune system as the first line of defence against pathogen invasion [11]. NO is endogenously generated by the enzyme nitric oxide synthase (NOS), which catalyses the NADPH dependent reaction between L-arginine and $\mathrm{O}_{2}$, generating citruline plus $\mathrm{NO}$ (Eq. 1) [12].

$$
2 \mathrm{~L}-\text { Arginine }+3 \mathrm{NADPH}+\mathrm{H}^{+}+4 \mathrm{O}_{2} \rightarrow 2 \mathrm{NO}+2 \text { Citruline }+4 \mathrm{H}_{2} \mathrm{O}+3 \mathrm{NADP}^{+} \quad \text { Eq. } 1
$$

Endothelial and neuronal NOS enzymes are constitutively expressed and produce low levels of $\mathrm{NO}$ regulated mainly by $\mathrm{Ca}^{2+}$. Inducible NOS is associated with the immune system and produces high concentrations of NO. For example, leukocytes were reported to produce NO metabolites $\left(\mathrm{NO}_{x}\right)$ in the range $12-37 \mu \mathrm{M}$ [13], while neutrophils and macrophages are capable of producing concentrations $>10 \mu \mathrm{M} \mathrm{NO}$ when stimulated [14, 15]. The macrophage phagosome provides an environment that is highly acidic, with $\mathrm{pH}$ values as low as 4.5 , and oxidative, with reactive oxygen species (ROS), $\mathrm{O}_{2}{ }^{-*}$ and $\mathrm{H}_{2} \mathrm{O}_{2}$. It also contains lytic enzymes that digest engulfed pathogens. The action of nitric oxide synthase (iNOS) greatly strengthens the anti-bacterial capabilities of the macrophage [16]. Pathogenic bacteria thus encounter high concentrations of external NO. However, NO is also generated endogenously by bacteria from nitrite ions under anaerobic conditions $[17,18]$ (this may also be a source of NO in eukaryotes under hypoxia), and there is growing evidence that NO functions in regulatory processes in bacteria $[19,20]$.

NO is a neutral free radical molecule; it contains an unpaired electron. Its molecular orbital diagram (Figure 2) shows that the unpaired electron resides in a $\pi^{*}$ orbital, with the unpaired spin density delocalised between the nitrogen $(\sim 0.6)$ and oxygen $(\sim 0.4)$ atoms. The bond length of free $\mathrm{NO}$ is $1.154 \AA$, consistent with a bond order of 2.5 . The radical nature of $\mathrm{NO}$ accounts for its reactivity, not only towards other radical molecules such as $\mathrm{O}_{2}$ and 
superoxide, but also with transition metal ions containing unpaired electrons [21-23]. The small dipole moment of $\mathrm{NO}$ means that it has limited solubility in aqueous solution $(<2 \mathrm{mM})$, but is highly soluble in hydrophobic environments. Thus, it can freely diffuse across biological membranes. Its high diffusion rate [24] and relatively low reactivity allow biological effects to take place at relatively long range: the diffusion distance of NO from an NO-releasing cell is estimated to be $100-200 \mu \mathrm{m}$ [25].

$<$ Figure 2 here $>$

The reduction potential for the NO/NO- couple is $-0.8 \pm 0.2 \mathrm{~V}$ versus SHE at $\mathrm{pH} 7$ [26], well below potentials available under physiological conditions. Thus the direct one-electron reduction to $\mathrm{NO}^{-}$(as $\mathrm{HNO}$ ) is highly unfavourable. Thus $\mathrm{NO}$ does not undergo one electron reduction reactions, in contrast to $\mathrm{O}_{2}$ which can generate superoxide, $\mathrm{O}_{2}{ }^{-*}$. NO is an effective inhibitor of respiratory enzymes that readily reduce $\mathrm{O}_{2}$. Similarly, $\mathrm{NO}$ does not readily undergo oxidation to form the $\mathrm{NO}^{+}$ion; the reduction potential for the $\mathrm{NO}^{+} / \mathrm{NO}$ couple is estimated to be $+1.2 \mathrm{~V}$ versus SHE [27].

Reactions of NO in the cell are complex. As mentioned above, NO reacts readily with other radicals, including $\mathrm{O}_{2}^{-*}$ and $\mathrm{O}_{2}$, resulting in a range of species, including nitrogen dioxide $\left(\mathrm{NO}_{2}\right)$, peroxynitrite (ONOO-), dinitrogen trioxide $\left(\mathrm{N}_{2} \mathrm{O}_{3}\right)$ and nitrite $\left(\mathrm{NO}_{2}{ }^{-}\right)$. This chemistry is often regarded collectively as nitrosative stress although technically this term refers to uncontrolled nitrosation reactions involving additions of $\mathrm{NO}^{+}$to biomolecules. (See Heinrich et al. for a detailed description of the nomenclature associated with biologically relevant reactions involving NO [28]). Clearly, some of the toxic effects of NO are mediated via these species. $\mathrm{ONOO}^{-}$is generated by the diffusion limited reaction of $\mathrm{NO}$ with $\mathrm{O}_{2}{ }^{-}$[29]. Peroxynitrite, which exists at least partially in its protonated $\mathrm{ONOOH}$ form, is itself highly toxic, undergoing a range of reactions leading to oxidation of thiols and lipids, and nitration and hydroxylation of aromatic residues [22]. However, because $\mathrm{O}_{2}{ }^{-}$cannot cross membranes, where it is produced is important when considering the likely impacts of peroxynitrite toxicity. For example, inside the macrophage phagosomal lumen, $\mathrm{O}_{2}{ }^{-*}$ is generated along with $\mathrm{NO}$, enhancing the antimicrobial action of the macrophage.

Although $\mathrm{NO}$ and $\mathrm{O}_{2}$ may be overall at a low concentration, because of their lipophilicity both can concentrate in membranes and hence undergo rapid reaction leading to the generation of nitrogen dioxide $\left(\mathrm{NO}_{2}\right)$, another radical species, that can nitrate tyrosine residues to form 3-nitrotyrosine [30]. $\mathrm{NO}_{2}$ also can dimerise to form $\mathrm{N}_{2} \mathrm{O}_{4}$, which in aqueous solution decomposes to $\mathrm{NO}_{2}{ }^{-}$and $\mathrm{NO}_{3}{ }^{-}$. Under acidic conditions, such as in the macrophage phagosome, $\mathrm{NO}_{2}$ can decompose via $\mathrm{HNO}_{2}$ and $\mathrm{N}_{2} \mathrm{O}_{3}$ to $\mathrm{NO}$ and $\mathrm{NO}_{2}$ [31]. $\mathrm{NO}_{2}$ can also react in aqueous solution with $\mathrm{NO}$ to give $\mathrm{N}_{2} \mathrm{O}_{3}$, an effective nitrosating reagent of cysteine side chains, leading to the formation of S-nitrosothiols. It should also be noted that because $\mathrm{NO}$ rapidly reacts in the presence of $\mathrm{O}_{2}$, build-up of detectable concentrations of $\mathrm{NO}$ is associated with hypoxia, and may be a signal of low $\mathrm{O}_{2}$ concentrations in vivo [32].

The specific and coordinated S-nitrosation of Cys residues is now well established as a post-translational form of regulation [33], and is one of the most important ways in which NO functions. The biological chemistry by which S-nitrosothiols are formed is still uncertain, but includes cysteine oxidation, metal ion catalysis; trans-nitrosation reactions between proteins, principally by S-nitroso-thioredoxin, and low molecular weight thiols, such as S-nitrosoglutathione (GSNO) [34].

Other major routes of $\mathrm{NO}$ function and toxicity are through its reaction with transition metal ions (principally iron) to form metal-nitrosyl complexes. Most famously, its ability to form a nitrosyl complex with iron in the heme group of soluble guanylate cyclase, along with its capacity to act over long range, underpins its function as a secondary messenger [35]. Binding to this enzyme activates catalysis of cGMP production, with the ensuing activation of cGMPdependent kinases promoting a network of signalling processes via protein phosphorylation. As described later, NO can form many other nitrosyl species, particularly with iron. These may form when NO levels are not adequately regulated and, through the loss of function of metalcofactor containing proteins, are another important way that NO exerts toxicity. However, they 
may also underlie signalling responses in which the NO signal is transduced through the formation of iron-nitrosyl species.

\subsection{The biology of NO sensing via Fe-S cluster proteins}

Fe-S cluster proteins are highly susceptible to reaction with $\mathrm{NO}$ and represent a major route of NO-mediated toxicity when cellular NO concentrations are high, e.g. in the micromolar range. In order to survive the deleterious effects of $\mathrm{NO}$ [36], organisms, including pathogens during infection of a human host, must be able to detect and respond to this chemical assault. To do this, the inherent reactivity of Fe-S clusters with reactive nitrogen (and oxygen) species has been exploited through the evolution of proteins that function in sensing intracellular levels of NO. The NO signal is transduced via NO-stimulated protein conformational changes that alter DNA-binding affinities and thus the regulation of gene expression, enabling the organism to mount a response to minimize damage. Examples of $\mathrm{Fe}-\mathrm{S}$ regulators include the dedicated NO-sensor NsrR, and regulators such as SoxR and FNR (Fumarate and Nitrate Reduction), which also sense NO, although not as their primary function [37]. Enzymes involved in NO detoxification include flavohemoglobins, flavorubredoxin nitric oxide reductases, oxidase family NO reductases, and cytochrome $c$ nitrite reductases, each of which removes NO by conversion into less toxic molecules including nitrate, nitrous oxide and ammonia [38].

Organisms also respond to very much lower concentrations of NO (nanomolar), at which it functions as a signalling molecule. Aside from the well known sensing of $\mathrm{NO}$ in higher eukaryotes by the heme protein guanylate cyclase, it is becoming clear that NO also plays a signaling role in simpler organisms, including bacteria, where such pathways are now being uncovered. Proteins that belong to the same H-NOX family as the heme domain of guanylate cyclase (and share 15-40\% sequence identity) are encoded in many bacterial genomes. They are known to bind $\mathrm{NO}$ and to participate in signaling pathways and regulate bacterial processes such as quorum sensing, biofilm formation, and symbiosis (reviewed in [38]). NO signaling also occurs via S-nitrosation of Cys thiols in bacterial proteins [19], and there is growing evidence that $\mathrm{Fe}-\mathrm{S}$ proteins are involved in sensing $\mathrm{NO}$ as part of a signaling pathway. For example, the WhiB-like (Wbl) proteins found in actinomycetes, which contain a [4Fe-4S], regulate cell development processes such as sporulation, and are likely to function, at least in part, as NO sensors [39-41].

The way in which Fe-S cluster proteins (principally regulators) react with $\mathrm{NO}$ is the focus of much of this chapter. Of particular interest is the mechanism of the reactions and the chemical nature of intermediates, and products, formed when NO reacts with an Fe-S cluster protein.

\section{Biophysical techniques useful for studying Fe-S cluster reactions with NO}

Since the discovery of FeS proteins in the 1960s spectroscopic techniques, including EPR, Mössbauer, resonance Raman (RR) and magnetic circular dichroism (MCD) have been applied to identify and characterise Fe-S clusters within proteins. However, the identification of the chemical structures of iron-nitrosyl species and the ability to follow their reactions with $\mathrm{NO}$ has proved to be particularly challenging. Recently several new techniques have been developed that enable the vibrational spectra of protein-bound iron-nitrosyl species to be measured with the potential to provide full diagnostic resolution. This overview does not cover high resolution structural methods. Although X-ray crystal structures are available for many Fe-S cluster proteins, very few Fe-S cluster regulatory proteins have been structurally characterised, in part a consequence of their sensitivity to $\mathrm{O}_{2}$ and other reactive species. Thus, up to now, it has not been possible to access high resolution structural information about Fe$S$ cluster reactions with NO. Here, we briefly discuss both the well-established and more recent techniques that are proving useful for studies of $\mathrm{Fe}-\mathrm{S}$ cluster nitrosylation reactions. Examples where some of these methods have been applied to NO-sensing regulatory proteins are given in Section 4.

\subsection{Electron paramagnetic resonance (EPR) spectroscopy}


Electron paramagnetic resonance (EPR) spectroscopy is applicable to paramagnetic systems, i.e. those that contain unpaired electrons. Radical species clearly fall into that category, but EPR has also proven to be extremely useful for mechanistic studies of metalloproteins, including Fe-S clusters, because the transition metal ions they contain at their active sites have incomplete d-orbital shells and often possess unpaired electrons. Iron, for example, in both $\mathrm{Fe}^{2+}$ (high spin) and $\mathrm{Fe}^{3+}$ (high and low spin) oxidation states contains unpaired electrons and so in principle is detectable using EPR. For Fe-S cluster proteins, the complex magnetic coupling briefly mentioned above means that clusters are considered in terms of their total spin properties (where spins from each of the irons are coupled together). Antiferromagnetic coupling of individual spins is commonly the most favourable arrangement, and this can result in no net total spin $(S=0)$ and therefore no EPR signal. This is the case for both [4Fe-4S $]^{2+}$ and $[2 \mathrm{Fe}-2 \mathrm{~S}]^{2+}$ clusters. In contrast, the oxidised form of the $[3 \mathrm{Fe}-4 \mathrm{~S}]$ cluster (i.e. [3Fe-4S $]^{1+}$ ) is paramagnetic, with total spin, $\mathrm{S},=1 / 2$. Single electron reduction of $[4 \mathrm{Fe}-4 \mathrm{~S}]^{2+}$ and $[2 \mathrm{Fe}-2 \mathrm{~S}]^{2+}$ results in paramagnetic systems (usually $S=1 / 2$ ), which are readily detectable by EPR. The EPR spectrum of a Fe-S cluster in a paramagnetic state is characteristic (as described by a set of $g$-values) of the particular cluster, see Chapter $X$ of this volume for a detailed description of the EPR properties of Fe-S cluster proteins.

EPR played a key role in the first identification of an iron-nitrosyl in cells. The spectrum was a distinctive $S=1 / 2$ EPR signal at $g_{a v}=2.03\left(g_{\perp}=2.04, g_{\|}=2.014\right)$, see Section 3.1, assigned to the mononuclear iron dinitrosyl complex, $\left[\mathrm{Fe}(\mathrm{NO})_{2}(\mathrm{RS})_{2}\right]^{-}(\mathrm{DNIC})$. Detection by EPR was first definitively achieved in 1973 through studies of the reaction of nitrogenase with NO [42]. Similar signals had been observed even earlier, in the 1960s, in EPR studies of animal tissue and cells, providing the first evidence that NO toxicity is, at least in part, mediated via its targeted reaction with Fe-S cluster proteins [43, 44]. Subsequently, quantitative studies of Fe-S cluster nitrosylation reactions in vitro confirmed that DNICs are formed, but importantly revealed that, in many cases, they account for only a small percentage of the initial cluster concentration/total cluster iron (see [41] and references therein) suggesting that the majority of the iron was in an EPR silent form. Other possible iron-nitrosyl products, for example, Roussin's red ester, [ $\left.\mathrm{Fe}_{2}(\mathrm{NO})_{4}(\mathrm{RS})_{2}\right]$, (RRE, see later), are diamagnetic and thus EPR silent. One electron reduction of RRE to generate $S=1 / 2 \mathrm{rRRE}$ may be possible, as demonstrated following addition of $\mathrm{NO}$ to the [2Fe-2S] cluster of the Rieske protein toluene/o-xylene monooxygenase component C (ToMOC) from Pseudomonas sp. OX1 [45]. Nitrosylation gave rise to an EPR spectrum with the characteristic $g_{\mathrm{av}}=2.03$ signal, but this accounted for only $\sim 20 \%$ of the total iron. Addition of the reductant sodium dithionite gave rise to a new EPR spectrum containing an axial signal with $\mathrm{g}_{\perp}=2.008$ and $\mathrm{g}_{\|}=1.971$, arising from rRRE, and accounting for $\sim 70 \%$ of cluster iron.

\subsection{Mössbauer spectroscopy}

Mössbauer spectroscopy is one of the most useful and important techniques for studies of Fe$S$ cluster proteins, and is described in detail in Chapter $\mathrm{X}$. One of the major advantages of the technique, which is a high energy ( $\mathrm{y}$-ray) technique that measures nuclear transitions, is that it is iron-specific, i.e. all the signals are due to iron transitions and so it does not suffer from background interference. Furthermore, all of the iron in the sample gives rise to a signal, so it is not dependent on the iron being in a particular state. The spectral parameters, isotope shift $(\delta)$ and quadrupole splitting $\left(\Delta \mathrm{E}_{\mathrm{Q}}\right)$, reported as a velocity $\left(\mathrm{mm} \mathrm{s}^{-1}\right)$, provides detailed information about the electronic configurations (oxidation and spin state) of the irons. While this is invaluable for determining the type and redox state of Fe-S clusters, and is also useful for following reactions of Fe-S clusters with NO, it is less useful for identifying the precise nature of the iron-nitrosyl species formed [45]. This is because the Mössbauer parameters of various iron dinitrosyls are similar, with $\delta=\sim 0.15-0.17 \mathrm{~mm} \mathrm{~s}^{-1}$ and $\Delta E_{\mathrm{Q}}=\sim 0.7-1.0 \mathrm{~mm} \mathrm{~s}$ ${ }^{1}[45-47]$.

\subsection{Infra-red (IR) spectroscopy}

Infra-red (IR) spectroscopy is routine for the characterisation of inorganic small molecule complexes that mimic protein-associated cofactors. The use of IR in studies of metallo-centres 
in proteins is generally hampered by the fact that vibrations of the amide protein backbone and of the aqueous solvent often overlap and obscure regions of the spectrum that are of interest. In certain favourable cases, where the protein cofactor is highly stable and a single $\mathrm{NO}$ is bound, such as in NO-bound myoglobin, the background problem can be overcome using techniques such as photolysis difference FT-IR, where the spectra are recorded before and after the NO is photolysed off and the difference corresponds to bound NO vibrations [48]. This approach is not straightforward for nitrosylated Fe-S proteins because of the unpredictable effects of photolysis of nitrosylated species. Recently, the Vincent group in Oxford have begun to develop attenuated total reflectance (ATR) IR spectroscopy in order to provide insight into Fe-S protein nitrosylation. The particular advantage of this method is that it has a small sample volume requirement (ca $7 \mu \mathrm{L}$ ) and an effective pathlength that is much shorter than in a standard IR experiment, helping to overcome the background problems mentioned above. They reported the detection of DNIC and RRE species (depending on $\mathrm{pH}$ and extent of $\mathrm{O}_{2}$ exposure), with distinct IR signatures, following nitrosylation of a [2Fe-2S] ferredoxin [49]. The DNIC spectrum contained features at 1762 and $1726 \mathrm{~cm}^{-1}$, while the RRE spectral features were at 1815, 1783 and $1757 \mathrm{~cm}^{-1}$, in good agreement with small peptide DNIC and RRE model complexes [50]. This method offers significant potential for future analysis of NO-sensing regulatory proteins upon reaction with $\mathrm{NO}$.

\subsection{Resonance Raman spectroscopy}

Resonance Raman (RR) spectroscopy is a technique that has up to now provided the most insight into the vibrational modes of the core Fe-S clusters. The selective excitation of these modes occurs via scattering of the optical absorption bands arising from Fe-S core electronic transitions [51]. It is complementary to IR spectroscopy in terms of the information it provides but does not suffer the same solvent background interference problems that have hindered that application of IR methods. The RR spectrum is a reliable indicator of cluster the type and coordination by the protein. For example, at low temperatures the frequency of the intense symmetric Fe-S stretching mode of the $[4 \mathrm{Fe}-4 \mathrm{~S}]^{2+}$ core in all cysteinyl-ligated $[4 \mathrm{Fe}-4 \mathrm{~S}]^{2+}$ clusters typically falls in the range 333-339 $\mathrm{cm}^{-1}$, while for those with one oxygenic ligand (Asp or Ser) the frequency is in the range $340-343 \mathrm{~cm}^{-1}[52,53]$. Furthermore, histidine coordination of a [2Fe-2S] cluster is characterised by the presence of two bands in the $250-305 \mathrm{~cm}^{-1}$ low frequency region, compared to only one broad band in the spectrum of a similar cluster with all Cys coordination, or with one Ser, Asp or Arg residue in place of one Cys [54-57]. Because several Fe-S cluster regulatory proteins have non-all Cys cluster coordination, RR is potentially useful for their characterisation [58]. Unfortunately, despite the utility of RR for studies of Fe-S proteins, it has not been applied to studies of Fe-S nitrosylation reactions. This is due, in part, to the photo-lability of these complexes, causing sample degradation to occur during laser excitation of the nitrosyl electronic transitions.

\subsection{Nuclear resonance vibrational spectroscopy (NRVS)}

Nuclear resonance vibrational spectroscopy (NRVS), also known as nuclear inelastic scattering (NIS) spectroscopy, probes vibrational states through the scattering of $y$-rays. [59, $60]$. The elastic component of the ${ }^{57} \mathrm{Fe}$ nuclear transitions are detected in Mössbauer spectroscopy giving the energies of the nuclear states. During inelastic scattering the photon gains or loses energy by excitation of vibrational modes coupled to the Fe nucleus. Thus, NRVS is selective for Mössbauer active nuclei and has great potential for providing novel insight into iron $\left({ }^{57} \mathrm{Fe}\right)$-containing metalloproteins. One of its advantages is that it is selective for vibrations involving displacement of the iron nuclei, and so does not suffer background interference effects. Furthermore, it is not limited by the selection rules of IR and Raman spectroscopies, and so provides a complete set of vibrational motions involving iron. NRVS is ideal for the identification of metal-ligand stretching vibrations because it samples the kinetic energy distribution of the vibrational modes, thus the band intensities are proportional to the amount and direction of the iron motion in a normal mode.

Like Raman, NRVS measurements report on a very inefficient scattering process. Thus, an intense $y$-ray source is needed such as a synchrotron. It also requires ${ }^{57} \mathrm{Fe}$ 
enrichment and millimolar concentrations of sample. The fragility of Fe-S cluster proteins that function as sensors of small molecules such as $\mathrm{O}_{2}$ and $\mathrm{NO}$ have hampered efforts to apply NRVS but progress is now being made [61-64]. NRVS was recently used to study the NO reactions of a [4Fe-4S] ferredoxin and a [2Fe-2S] Rieske-type protein. These showed that the iron-nitrosyl species Roussin's Black Salt (RBS) and RRE, respectively, were the final products of nitrosylation rather than DNICs $[45,46]$, thus demonstrating the potential of the technique to provide unambiguous identification of iron-nitrosyl species during and following Fe-S cluster nitrosylation.

\subsection{Stopped-flow absorbance spectroscopy}

UV-visible absorbance spectroscopy is useful for the characterisation of iron-nitrosyl species. DNIC species give absorbance spectra with a major band at just below $400 \mathrm{~nm}\left(\varepsilon=\sim 3600 \mathrm{M}^{-}\right.$ $\left.{ }^{1} \mathrm{~cm}^{-1}\right)$ and further, weaker bands at $\sim 600$ and $770 \mathrm{~nm}\left(\varepsilon=\sim 300 \mathrm{M}^{-1} \mathrm{~cm}^{-1}\right)$ [65]. Absorbance spectra of the more complex iron-nitrosyls are different. RRE species give intense bands at $\sim 310 \mathrm{~nm}\left(\varepsilon=\sim 9650 \mathrm{M}^{-1} \mathrm{~cm}^{-1}\right)$ and $\sim 360 \mathrm{~nm}\left(\varepsilon=\sim 8530 \mathrm{M}^{-1} \mathrm{~cm}^{-1}\right)$ with a shoulder at $\sim 430 \mathrm{~nm}$ $\left(\varepsilon=\sim 3500 \mathrm{M}^{-1} \mathrm{~cm}^{-1}\right)$ and much weaker band at $\sim 750 \mathrm{~nm}\left(\varepsilon=\sim 100 \mathrm{M}^{-1} \mathrm{~cm}^{-1}\right)$ [65]. The spectrum of RBS is somewhat similar to that of RRE, with major peaks at 270 and $360 \mathrm{~nm}$ and weaker bands at 420 and $\sim 600 \mathrm{~nm}$ [66]. One of the most useful applications of absorbance spectroscopy in studies of Fe-S cluster nitrosylation reactions is in rapid reaction measurements. Here, stopped-flow rapid mixing of Fe-S cluster protein and a solution of NO is combined with absorbance data acquisition to provide the kinetic characteristics of the reaction at selected wavelengths corresponding to the initial Fe-S cluster (e.g. $\sim 420 \mathrm{~nm}$ ) and to the newly formed iron-nitrosyl (e.g. $\sim 360 \mathrm{~nm}$ ) [41, 67, 68]. This has revealed that the nitrosylation reaction of $\mathrm{Fe}-\mathrm{S}$ cluster regulatory proteins is a multi-step reaction, involving multiple (8-10) NO molecules per cluster, which reaches completion within a few seconds. By measuring reaction rates as a function of $\mathrm{NO}$ concentration, the order of reaction with respect to NO can be determined, providing important mechanistic information.

\subsection{Electrospray ionisation mass spectrometry}

Mass spectrometry can provide accurate masses for a wide range of molecular species, including proteins. Normally, the mass information is for the intact but denatured protein. This is useful, particularly for protein identification, and for characterisation of post-translational covalent modifications, but it does not provide information about non-covalently bound cofactors. However, the coupling of soft electrospray ionisation (ESI) with solution and ionization conditions under which proteins remain folded has provided important new insights into non-covalent interactions for a range of biomolecules [69-72], including several Fe-S cluster proteins, where the cluster bound forms of the protein was detected [58, 73, 74]. Early studies reported the use of ESI and ion cyclotron resonance MS to study [4Fe-4S] ferredoxins [73]. The very high resolving power of the ion cyclotron resonance mass analyser permitted unambiguous determination of cluster oxidation states. A disadvantage of this technique is the high cost of these instruments. More recently, improvements in the resolution offered by Time Of Flight (TOF) mass analysers enables the cheaper ESI-TOF instruments to provide information about the type of cluster bound by Fe-S proteins. Although ionisation conditions require optimisation on a protein to protein basis, characterisation of two $\mathrm{Fe}-\mathrm{S}$ regulatory proteins has been reported recently $[58,74]$ and clearly this technique has potential for studying the reactivity of these clusters, including with NO.

\section{Metal nitrosyls}

\subsection{The metal - NO bond}

The metal-NO bond is highly covalent and the oxidation state of the metal ion is ambiguous. By convention developed by Enemark and Feltham [75], the metal-nitrosyl is considered as a unit when attributing a formal oxidation state, using the electron count of the metal $\mathrm{d}$ and $\mathrm{N} \mathrm{m}{ }^{*}$ orbitals, with the assumption of no formal charge on the NO. The electron count of the 
complex ion is used to assign charge to the ion as a whole, and formal charges to the metal ions. This becomes more complex when considering clusters containing multiple metalnitrosyl centres. In such cases the entire cluster as a unit is assigned a formal oxidation state, based on the number of $d$ electrons, again with the assumption of no formal charge on the NO ligand or ligands. The formal charges on individual metal atoms in Fe-S cluster based nitrosyl complexes are treated in the same way as are Fe-S clusters in general.

The stable radical NO, when bound in square pyramidal or hexacoordinate metal complexes, assumes an electronic configuration consistent with the nitrosyl $\left(\mathrm{NO}^{+}\right)$cation, which is isoelectronic with the carbonyl ligand $\mathrm{CO}$ and the cyano ligand $\mathrm{CN}^{-}$, though compounds in which the ligand has more nitroxyl (NO-) character are known as well. The $\mathrm{M}$ $\mathrm{N}-\mathrm{O}$ bond angle can reflect this, with basic valence theory predicting a linearly-bound NO with a triple $\mathrm{N}-\mathrm{O}$ bond and IR absorbance in the range $\mathrm{V}_{\mathrm{NO}}=1650-1900 \mathrm{~cm}^{-1}$ for nitrosyl and a bent bound form with double $\mathrm{N}-\mathrm{O}$ bond and IR absorbance in the range $\mathrm{V}_{\mathrm{NO}}=1525-1690 \mathrm{~cm}^{-1}$ for nitroxyl. The actual degree of nitrosyl or nitroxyl character is determined by the ligand environment of the metal ion and of course the metal itself, and is best described by molecular orbital theory, which provides a more nuanced description of the nature of the bond. NO is both an excellent $\sigma$ donor and $\pi$ acceptor, and the M-NO bond usually involves a high degree of $\pi$-back bonding from the metal $\mathrm{d}_{\pi}$ to $\mathrm{N} \pi^{*}$ orbitals. In a bond with a particularly electrophilic metal centre, the $\sigma$ donation from the $\mathrm{N}$ would predominate, increasing nitroxyl character [23]. Likewise, the $v_{N O} I R$ absorbance is dependent on the electronic configuration, charge, and ligand environment of the metal ion and thus reflects much more than just whether the bond is bent or straight.

Understanding of the differences in NO binding in tetrahedral complexes has advanced in recent years. Until recently iron-nitrosyl complexes were commonly described as above, with $\pi^{*}$ orbitals of a formally $\mathrm{NO}^{+}$ion interacting with iron valence $d$ shell exhibiting relatively normal tetrahedral field splitting. The most current studies, however, indicate that bound nitrosyl is actually more readily modelled when treated as $\mathrm{NO}^{-}$than $\mathrm{NO}^{+}$. Neese et al performed density functional theory (DFT) calculations on a series of 1,3-diketimine (nacnac) ligand-based dinitrosyl iron complexes (DNICs, Figure 3) for which complementary structural and spectroscopic data was available, and developed a model to fit the observed $\mathrm{N}-\mathrm{O}$ bond lengths in the reduced and oxidized species [76]. In this model, the $\mathrm{Fe} 3 \mathrm{~d}_{\mathrm{x} 2 \mathrm{y} 2 \mathrm{z}}$ orbital is essentially non-bonding, while the remaining four $\mathrm{Fe} 3 \mathrm{~d}$ orbitals form spin-coupled pairs with the $\pi^{*}$ orbitals of the NO. This work was limited to the N-based rigid bidentate nacnac ligand, and though the model had good correlation with experiment in terms of bond length and Mössbauer data, the IR fit was relatively poor. An earlier DFT study also found that a partially reduced NO provided a better representation for Roussin's black salt (RBS, Figure 3) [66]. The two studies fit well with experimental data overall and support a partially reduced bound NO ligand in these 4-coordinate tetrahedral complexes.

\section{$<$ Figure 3 here>}

Here we concentrate on the nitrosyl derivatives of various Fe-S clusters, which, like their parent clusters, are tetrahedral in geometry about the iron and can be thought of as having a delocalized shared-valence core rather than fixed charge states on the individual iron atoms. There is a large literature on heme nitrosyl complexes and other 5- and 6- coordinate iron-nitrosyl species, which is beyond the scope of this work.

\subsection{Iron-nitrosyl complexes}

The complexes named after the French chemist François-Zacharie Roussin are the best known of the Fe-S nitrosyl species. These complexes (Figure 3), first reported in 1858 [77], were the first synthetic Fe-S cluster complexes [78]. Roussin's black salt (RBS) anion, which has the formula $\left[\mathrm{Fe}_{4}(\mu-\mathrm{S})_{3}(\mathrm{NO})_{7}\right]^{-}$and was first described as the sodium salt, is diamagnetic (i.e. has net $S=0$ ) [66] and is thus EPR silent. Crystal structures have been reported with other cations, including ammonium and caesium [79] and in all cases the C3 symmetry of the anion is conserved. The classic anion can be readily prepared by the reaction of iron(II) sulfate with 
a mixture of sodium nitrite and ammonium sulfide, followed by crystallization of the ammonium salt of RBS from the resulting intensely black solution. As mentioned above, Jaworska and Stasicka [66] used DFT calculations to describe the electronic structure of RBS as comprising one ferric ion ( $S=5 / 2)$ antiferromagnetically coupled to a single $\mathrm{NO}^{-}$ligand $(S=1)$ giving $S=3 / 2$, which is then antiferromagnetically coupled to three ferric ions $(S=5 / 2)$ each of which are antiferromagnetically coupled to two $\mathrm{NO}^{-}$ligands with $S=1$ to give a total spin of $S=0$. The $\mu$ $S^{2-}$ bridges were found to mediate in the antiferromagnetic coupling. RBS can be reduced with a redox potential ( $\mathrm{V}$ vs SCE) of $\mathrm{E}_{-1 / 2}=-0.68, \mathrm{E}_{-2 /-3}=-1.26$, and $\mathrm{E}_{-3 /-4}=-1.75$. The one electron reduced form of RBS has also been isolated as an ammonium salt which exhibits an EPR spectrum that suggests the presence in solution of a mixture of two paramagnetic species [80]. The un-reduced RBS has nitrosyl IR frequencies at 1715, 1745 and $1800 \mathrm{~cm}^{-1}$ which vary little with different counter ions [81].

Though it is the most stable of the Fe-S cluster nitrosyls, under alkaline conditions RBS can undergo conversion to the related species 'Roussin's red salt' (RRS), the anion of which has the formula $\left[\mathrm{Fe}_{2}(\mu-\mathrm{S})_{2}(\mathrm{NO})_{4}\right]^{2-}$. It, too, is diamagnetic, and thus EPR silent. The '2-' salt has two IR nitrosyl signals at $v_{\mathrm{NO}}=1717$ and $1677 \mathrm{~cm}^{-1}$ [81]. The structure of the first 'Roussin's red ester', of the basic formula $\mathrm{Fe}_{2}(\mu-\mathrm{SR})_{2}(\mathrm{NO})_{4}$ was published in 1958 [82]. In these complexes the bridging sulfide ions of RRS are replaced with bridging alkyl or aryl thiolates. The salt and ester are often considered together as they are related by structure. The oneelectron reduced form of the ester is also known, is EPR active with $S=1 / 2$, and features a slightly elongated Fe-Fe distance [83].

The tetrahedral mononuclear dinitrosyl iron complexes (DNICs) have the general form $\left[\mathrm{Fe}(\mathrm{NO})_{2} \mathrm{~L}_{2}\right]^{\mathrm{x}+}$, where $\mathrm{L}$ is any of a wide variety of ligands, though in most examples it is a thiolate. $\mathrm{N}$ - and $\mathrm{P}$ - based ligands are also well known. The form $\left[\mathrm{Fe}(\mathrm{NO})_{2}(\mathrm{SR})_{2}\right]^{-}$is structurally similar to RRE, and the two are readily interconverted. DNICs are paramagnetic $(S=1 / 2)$ with a characteristic g-value of $\approx 2.03$ that is consistent across all ligands. They exhibit distorted tetrahedral geometry and roughly linear Fe-NO bonds, and EPR, IR, and crystallographic structural data are available for a very large range of complexes of this type [84, 85]. As described above, DFT calculations combined with spectroscopic observations revealed that that the $S=1 / 2 \mathrm{DNIC}$, which is represented as $\left\{\mathrm{Fe}(\mathrm{NO})_{2}\right\}^{9}$ in the Enemark-Feltham notation, is best described by two resonance structures consisting of a high spin $\mathrm{Fe}^{3+}(S=5 / 2)$ antiferromagnetically coupled to two $\mathrm{NO}^{-}$ligands (each $S=1$ ), and a high spin $\mathrm{Fe}^{2+}(S=2)$ antiferromagnetically coupled to an overall quartet ${ }^{4}(\mathrm{NO})_{2}{ }^{-}$ligand $(S=3 / 2)$ [76]. The type of ligand $L$ influences the distortion. Soft ligands, such as thiol, result in a distorted tetrahedron in which the $\mathrm{ON}-\mathrm{Fe}-\mathrm{NO}$ bond angle is reduced and the anionic ligands are pushed apart, possibly due to size of ligand. Hard, non-polarizable ligands (i.e. fluoride, methoxide) result in a flattened, almost square planar complex with increased solvent interaction.

In addition to these three main types of iron-nitrosyl, the neutral and one-electron reduced $\mathrm{Fe}_{4}(\mu-\mathrm{S})_{4}(\mathrm{NO})_{4}$ (tetranitrosyl-tetra- $\mu_{3}$-sufidotetrahedro-tetrairon) species have been isolated synthetically and the first is known to be an intermediate in the conversion between $\left[\mathrm{Fe}_{4}(\mu-\mathrm{S})_{4}(\mathrm{~L})_{4}\right]^{2-} \mathrm{Fe}-\mathrm{S}$ clusters and the more stable DNIC and RBS products via nitrosylation [86-88].

Small molecule iron-nitrosyl species are regarded as biologically active due to their solubility in both aqueous and lipophilic media and release of NO under certain conditions. Whether they have biological functions in vivo, for example in storing, transportation, and delivery of NO to relevant targets, is currently unknown. All three classes of iron-nitrosyl species have been investigated for NO donor ability in biological systems. Attempts to develop therapeutic photochemically induced NO-delivery systems for radiation sensitization of targeted cancer tissue revealed that RRS, on photolysis, gives the more stable and cytotoxic RBS, which, though less photoactive, can decompose photolytically to release NO and ferric precipitates [81].

Free NO is cytotoxic, and hypoxic cells treated with the red salt and white light showed increased susceptibility to $\mathrm{y}$ radiation damage as well. Water-soluble RRE complexes have similar effects [89]. RBS and RRE have demonstrable bactericidal effects, and RBS has been shown to induce the relaxation of animal vascular smooth muscle tissue associated with the 
vasodilation induced by increased $\mathrm{NO}$ concentration as introduced from other sources or carriers, even in the absence of light. We note that the red salt has also been reported to have carcinogenic properties as well.

\subsection{Formation and interchange of Fe-S cluster nitrosyl species}

Synthetic Fe-S cluster species yield iron-nitrosyl species upon reaction with excess NO. There is also extensive evidence for this chemistry in biological systems (see section 4). The various nitrosylated clusters are chemically interchangeable in tunable ways, adding complexity to the possible pathways between initial nitrosylation and final observed iron-nitrosyl product (Figure 4). RBS can be converted to RRE structures by reaction with organohalides [90, 91], or via nucleophilic attack of the $\mathrm{S}^{2-}$ on highly electrophilic diazonium $\left(\mathrm{RN}_{2}{ }^{+}\right)$and onium $\left(\mathrm{R}_{3} \mathrm{O}^{+}\right)$ions [92], and reaction of RBS with RS nucleophiles leads to formation of octahedral $\left[\mathrm{Fe}(\mathrm{SR})_{2}(\mathrm{NO})_{4}\right]^{2-}$ and tetrahedral $\left[\mathrm{Fe}(\mathrm{SR})_{3}(\mathrm{NO})\right]^{-}$MNIC species [93]. RRE species can undergo thiolate exchange in polar, coordinating solvents; addition of R'SH to $\mathrm{Fe}_{2}(\mu-\mathrm{SR})_{2}(\mathrm{NO})_{4}$ can lead to $\mathrm{Fe}_{2}\left(\mu-\mathrm{SR}^{\prime}\right)_{2}(\mathrm{NO})_{4}$ with loss of $\mathrm{RSH}$ [94].

$<$ Figure 4 here $>$

When an Fe-S cluster complex, biological or synthetic reacts with NO, the iron-nitrosyl product that is preferentially formed depends on the nature of the cluster, the redox state of the source NO, the presence of excess thiol or thiolate, the nature of the solvent environment, and the stoichiometry of the reaction (Figures 5,6). $\left[\mathrm{Fe}_{2} \mathrm{~S}_{2}(\mathrm{SR})_{4}\right]^{2-}$ complexes react with excess NO to yield DNICs with concomitant reductive elimination of the bridging sulfide ligands as elemental sulfur, while $\left[\mathrm{Fe}_{4} \mathrm{~S}_{4}(\mathrm{SR})_{4}\right]^{2-}$ complexes exposed to excess NO yield either RBS, or, in the presence of added thiolate, DNIC products [95]. Lippard et al found that synthetic Rieske-type model complexes $\left[\mathrm{Fe}_{2} \mathrm{~S}_{2}(\mathrm{SR})_{2}(\mathrm{NR})_{2}\right]^{2-}$ likewise result in thiolate and amine DNIC species upon nitrosylation in acetonitrile but attempts to repeat this with a representative Rieske protein yielded RRE products [45, 84]. Careful control of 1:1 stoichiometry for reaction of a simple tetrahedral $\left[\mathrm{Fe}(\mathrm{SR})_{4}\right]^{2-1 /}$ - complex with $\mathrm{NO}$ leads to the formation of the mononuclear tris(thiolate) mononitrosyl iron complex (MNIC) and either RS or RSSR depending on the oxidation state of the starting complex. The MNIC, upon exposure to sources of $\mathrm{NO}$ and $\mathrm{NO}^{+}$yields DNICs $\left(\left[\mathrm{Fe}(\mathrm{SR})_{2}(\mathrm{NO})_{2}\right]^{-}\right)$and RRE complexes $\left(\mathrm{Fe}_{2}(\mu-\mathrm{SR})_{2}(\mathrm{NO})_{4}\right)$ respectively, demonstrating the reliance of product species on the redox state of the NO source (Figure 5) [96, 97]. MNICs are widely accepted as intermediates in the stepwise nitrosylation of higher-order iron sulfur clusters en route to the more stable DNIC, RRE, and RBS products observed when NO is introduced in excess. All of these transformations are highly dependent on redox environment and solvent.

\section{$<$ Figure 5 here $>$}

The reversible interconversion of [2Fe-2S] clusters and DNICs is also well established. Fe-S bonds are highly covalent and mechanically labile and the complexes are prone to thiolate exchange reaction mechanisms $[97,98]$. DNICs can be readily formed from RREs in the presence of excess thiolate, and the reverse reaction is favoured in protic conditions. The same interconversion has been demonstrated in aqueous solvent for compounds bound to a peptide scaffold containing two cysteines [50]. Cysteine analogues have been observed to efficiently convert thiolate-bound MNICs to [2Fe-2S] clusters without the need for any other reagents, with the thiol as the source of bridging sulphide [99, 100]. The thermodynamically stable RBS can be prepared directly from mononuclear DNIC species through reaction with $\mathrm{S}_{8}$ via a bis- $\mu$-polysulfide dinitrosyl intermediate [87].

\subsection{Nitrosylated species can be converted back to [2Fe-2S] and [4Fe-4S] iron-sulfur clusters}

Liaw et al. have achieved synthesis of $\left.\left[\mathrm{Fe}_{4}(\mu-\mathrm{S})_{4}\right](\mathrm{SR})_{4}\right]^{2-}$ clusters from RBS via an isolable $\mathrm{Fe}_{4}(\mu-\mathrm{S})_{4}(\mathrm{NO})_{4}$ intermediate using thiolate exchange with a [Fe(SR) $]^{-}$compound [87] (Figure 
6). This was an attempt to model synthetically the IscS-mediated repair of DNICs formed from nitrosylation of [4Fe-4S] endonuclease and [4Fe-4S] IRP1 [101, 102]. The mononuclear iron reagent is converted to DNIC in this reaction. $\left[\mathrm{Fe}_{2}(\mu-\mathrm{S})_{2}(\mathrm{SR})_{4}\right]^{2-}$ can also be assembled from DNIC or one-electron reduced RRE through the concomitant reduction of, and sulfide abstraction from, triphenylmethanethiol or dimethytrisulfide, through a RRS intermediate, followed by ligand exchange with a $\left[\mathrm{Fe}(\mathrm{SR})_{4}\right]^{-}$compound [103]. These mechanisms depend on the lability of the Fe-S bond.

$<$ Figure 6 here $>$

\subsection{Effect of cluster protein environment on nitrosylation}

The redox potential of the environment plays an important role in the products of Fe-S cluster nitrosylation. Reactions of thiolate DNICs in the presence of $\mathrm{O}_{2}$ resulted in oxidation at the sulfur centres rather than at iron with consequent formation of a RRE product and disulfide [104]. [2Fe-2S] nitrosylation in an acidic reducing environment capable of providing an $\mathrm{e}^{-} / \mathrm{H}^{+}$ pair will lead to elimination of the bridging sulfides as $\mathrm{H}_{2} \mathrm{~S}$ rather than $\mathrm{S}^{0}$ [100] (Figure 6). $\mathrm{H}_{2} \mathrm{~S}$ has been established as another key biological gasotransmitter, and redox-dependent crosstalk between $\mathrm{H}_{2} \mathrm{~S}$ and $\mathrm{NO}$ has been proposed. $\mathrm{An} \mathrm{O}_{2}$-dependent distribution of DNIC and RRE products has also been observed using ATR IR in the nitrosylation of a [2Fe-2S] ferrodoxin [49]. NRVS has recently provided significant new information about the products following the nitrosylation of bacterial NO sensing [4Fe-4S] cluster proteins. The nitrosylation of these proteins is discussed at greater length in the following section of this chapter.

Holm et al. compiled an extensive comparison of crystallographically-determined volumes of clusters of the general formula $\left[\mathrm{M}_{4} \mathrm{Q}_{4} \mathrm{~L}_{4}\right]$, of which the $[4 \mathrm{Fe}-4 \mathrm{~S}](\mathrm{L})_{4}$ are representative, to demonstrate the relationship between geometry and cluster composition [105]. The cluster geometry exhibits high plasticity, in comparison to the stable Fe-S bond length, depending on the environment. Decreased Fe-Fe distances are accompanied by increased S-S distances, with the distortion reflected in the S-Fe-S angles. In particular increased electron donating ability of ligand $L$ was associated with longer Fe-Fe distances and a larger cluster volume. In keeping with this trend, redox state played a role as reflected in the shortening of $\mathrm{Fe}$-S distances and concomitant total cluster volume compression with increasing oxidation state and decreasing ionic radii. Fe-Fe distances were fairly constant in most examples, while the S-S distances reflected the change. Nitrosyl complexes, with the strong field, non-innocent NO ligand, bucked this trend, with Fe-Fe contacts decreasing on oxidation and increased metal-metal interaction [86].

This analysis of static structures can be extended to interpret the reactivity of Fe-S clusters to nitrosylation. The nitrosylation mechanism is believed to be initiated by chelation of the first $\mathrm{NO}$, displacing one of the external, weaker-field $\sigma$-donor ligands by an $\mathrm{S}_{\mathrm{N}} 1$ or $\mathrm{S}_{\mathrm{N}} 2$ type mechanism. The non-innocent nature of the NO ligand complicates this discussion, not least because the formalism of describing it as $\mathrm{NO}^{-}$is at best an oversimplification. The mechanism of the nitrosylation of biologically-relevant Fe-S species has yet to be fully elucidated, as there is limited data on intermediate species and the observable iron-nitrosyl products are sensitive to their environments and prone to interchange.

\section{Physiologically relevant reactions of NO with Fe-S cluster proteins}

\section{1 "Secondary" versus "Dedicated" biological NO sensors}

Before discussing the biological NO sensor regulators themselves, it is useful to consider their role in nitric oxide sensing. Transcriptional regulators reliant on heme, Fe-S clusters, nonheme iron, other transition metal ions, or even reactive cysteine residues may be perturbed by the presence of NO. As noted by Spiro [106], determining the physiological relevance of this can be a difficult issue, especially where limited in vivo or in vitro studies exists. A dedicated NO sensor can be thought of as one that detects NO, or related products such as S-nitroso-glutathione (GSNO), as a primary or sole analyte, and modulates the expression of 
gene(s) whose actions alleviate the toxic effects of these molecules. A secondary NO sensor would therefore primarily detect other analytes besides NO, and modulate the expression of genes that may be considered useful under conditions of nitrosoative stress.

With this in mind, NorR and NsrR can be considered to be dedicated NO sensors [107111]. While NsrR is an Fe-S cluster regulator and is discussed in detail below, NorR is a nonheme iron containing regulator that, when bound to NO, activates the transcription of NorVW, which encode the flavorubredoxin NorV and its associated oxidoreductase NorW [112]. Under anaerobic conditions, they function as a detoxifying $\mathrm{NO}$ reductase, converting NO to nitrous oxide $\left(\mathrm{N}_{2} \mathrm{O}\right)$. NsrR and NorR modulate the expression of genes that are immediately useful in mitigating the toxic effects of $\mathrm{NO}$ (e.g. hmp and norVW, respectively). In contrast, MetR and FNR would be considered secondary sensors as they primarily detect homocysteine and $\mathrm{O}_{2}$ (or the lack therefore), respectively $[113,114]$. We note that MetR and FNR play opposing roles in the regulation of $h m p$, activating and repressing, respectively, and that FNR induces $h c p$ (encoding an anaerobic NO reductase) as part of its regulon [115]. Others, such as SoxR, do not appear to fall into either category, despite being sensitive to NO, as they do not modulate genes that are immediately useful in dealing with NO. It is suggested that they may play a role in ensuring that detoxification enzymes have a steady supply of reducing equivalents $(\mathrm{NAD}(\mathrm{P}) \mathrm{H})$ and/or play a role in recovering from the effects of nitrosative stress $[116,117]$. Some of these sensors are discussed in detail in the following sections.

\subsection{NsrR}

\subsubsection{Function of NsrR as a NO sensor}

Many bacteria that carry out anaerobic respiration with nitrate/nitrite as a terminal electron acceptor can endogenously produce nitric oxide (NO). This may arise from adventitious reduction of nitrite $\left(\mathrm{NO}_{2}^{-}\right)$by nitrate $\left(\mathrm{NO}_{3}{ }^{-}\right)$reductases. In vivo many transcriptional regulators respond to the presence of aqueous NO, acidified nitrite or S-nitroso-glutathione; in E.coli these include MetR, IscR, Fur, FNR, SoxR, OxyR, NorR and NsrR (formally yjeB). In E. coli, NsrR was shown to sense $\mathrm{NO}$ and modulate a regulon of at least 60 genes, including nitrate (Nar) and nitrite reductase (Nir), as well as $h c p$ and $h m p$, which encode NO detoxifying enzymes [47, 109, 114, 118, 119].

While E. coli and B. subtilis NsrR proteins regulate multiple genes [107, 109], and the latter binds two different types of operator site (only one of which is dependent on the cluster) [107, 120], recent ChIP-seq experiments indicated S. coelicolor NsrR regulates only three genes: $h m p A 1, h m p A 2$ (both encoding NO detoxifying flavohaemoglobins) and $n s r R$ itself. Thus, unlike E. coli NsrR, S. coelicolor NsrR appears to have a specialized regulatory function focussed solely on $\mathrm{NO}$ detoxification, it is, therefore, not a global transcriptional regulator.

\subsubsection{NsrR is an Rrf2 family regulator}

NsrR belongs to the Rrf2 superfamily of transcriptional regulators. Although the archetypal member Rrf2 from Desulfovibrio vulgaris has not been well characterized [121], other well studied members include CymR, SaiR, IscR, RirA and RsrR. While CymR and SaiR represent regulators that do not contain a co-factor $[122,123]$, IscR, RirA, RsrR and NsrR contain three conserved cysteine residues (Figure 7) that have been shown, or are predicted, to bind an Fe$\mathrm{S}$ cluster, with the type, [2Fe-2S] or [4Fe-4S], being dependent on the particular regulator [58, $68,74,124,125]$. For example, IscR and RsrR are known to contain a [2Fe-2S] cluster, whereas NsrR from both Bacillus subtilis and Streptomyces coelicolor has been shown to bind a [4Fe-4S] cluster [58, 68, 74, 125, 126]. In all examples, where data are available, the Fe-S functions as the sensory module. High resolution structural information is available for both CymR and IscR in the cluster-less apo form (Figure 8). Structures of IscR in the free form and in complex with type 2 promoter DNA (to which holo- and apo-IsrR binds) have been reported $[122,125]$. Both proteins consist of a DNA binding domain, a dimerization helix and, in the case of IscR, a sensory domain. In this respect, CymR is unusual in that it performs its regulatory function through reversible complex formation with CysK, a key enzyme of cysteine biosynthesis [127]. 
$<$ Figure 7 here $>$

$<$ Figure 8 here $>$

\subsubsection{NsrR binds a [4Fe-4S] cluster}

A range of biophysical techniques revealed that NsrR purified under anaerobic conditions is a dimer containing one $[4 \mathrm{Fe}-4 \mathrm{~S}]^{2+}$ cluster per monomer. Figures 9 and 10 show representative data for NsrR (before and after addition of NO) from some of these techniques (see section 2), illustrating their application. Resonance Raman data were consistent with an Fe-S cluster coordinated by three cysteines and one oxygen-containing residue, rather than a histidine residue as found in IscR $[58,68]$. Moreover, some low molecular weight thiols (such as DTT) were found to modify the [4Fe-4S] cluster $[58,126]$, drastically reducing its $\mathrm{O}_{2}$ stability leading to rapid disassembly into a [2Fe-2S] [58]. Importantly, physiological thiols, such a cysteine, glutathione, or an analogue of mycothiol, did not induce cluster conversion. Where exogenous thiol binding was observed, it most likely competes for one of the iron sites, most likely the unique site that is not coordinated by cysteine. Together, these data help to account for early observations of a [2Fe-2S] cluster in S. coelicolor NsrR purified aerobically in the presence of DTT [128]. Attempts to identify the fourth oxygenic ligand have not thus far yielded a clear answer. Glu/Asp to Ala variants, in which carboxylic acid residues located near to the clustercoordinating Cys motif were substituted, were all found to contain a cluster and to retain some degree of DNA-binding. E85A was the most severely affected in terms of DNA binding and is therefore the best candidate, but caution is required in this assignment because indirect effects of site-directed substitutions are possible. Currently, we are not aware of an unambiguous example of cluster coordination by a three Cys and one Glu residue, but several instances of [4Fe-4S] clusters coordinated by three Cys and one Asp are known [58, 129-131].

$<$ Figure 9 here $>$

$<$ Figure 10 here>

Through a combination of electrophoretic mobility shift assays (EMSA) and DNasel foot-printing, S. coelicolor [4Fe-4S] NsrR was shown to bind site specifically and tightly, to an $11 \mathrm{bp}$ inverted repeat sequence within the promoter regions of the identified target genes [58]. The binding interaction between NsrR and the $h m p A 1$ promoter was the tightest, with full binding observed at a ratio of [4Fe-4S] NsrR monomer to DNA of approximately 2:1 (i.e. one NsrR dimer per DNA) [68]. This is significantly tighter than that previously reported for the [2Fe-2S] form, for which full binding of $h m p A 1$ promoter was not observed even with a several hundred-fold excess of protein [58]. Binding of [4Fe-4S] NsrR to $h m p 2 A$ and $n s r R$ promoters was weaker, with full binding occurring at ratios of $\sim 8$ and $\sim 5$, respectively; again, [2Fe-2S] and apo-forms of NsrR displayed little or no affinity for the same promoters.

\subsubsection{Nitrosylation of [4Fe-4S] $\mathrm{NsrR}$}

Exposure of NsrR to increasing concentrations of $\mathrm{NO}$ eventually abolished binding to all promoter fragments. Binding of [4Fe-4S] NsrR to $h m p A 2$ was reduced by $50 \%$ at a ratio of $\sim 1.4$ [NO]:[4Fe-4S], and lost entirely by a ratio of $\sim 2.5$ [132]. For $h m p A 1$ equivalent ratios were $\sim 2.3(50 \%)$ and $\sim 4.2$ (complete loss), while for the $n s r R$ promoter ratios were $\sim 4.1(50 \%)$ and 8.2 (complete loss). These data demonstrate an interesting, but poorly understood effect, which is presumably governed by the specific promoter sequence. They also suggest that hmpA2 may be preferentially activated by low concentrations of NO. To the best of our knowledge, Streptomyces $h m p$ proteins have not yet been studied, and so the significance of these observations is not yet clear.

Nitrosylation was also investigated optically, by measuring changes in the absorbance and circular dichroism (CD) properties of the Fe-S cluster [68]. Following the sequential addition of sub-stoichiometric amounts of NO, changes in the absorption bands of the cluster were observed. The final spectrum, corresponding to the addition of $\sim 11 \mathrm{NO}$ per cluster, had an absorption maximum at $360 \mathrm{~nm}$ and a shoulder at $\sim 430 \mathrm{~nm}$, consistent with the formation of iron-nitrosyl species similar to RRE (Figure 10). No isosbestic points were observed during 
the titration, suggesting the reaction pathway is complex involving several intermediates. A plot of absorbance changes versus the ratio of $\mathrm{NO}$ to cluster showed the reaction to be complete at a stoichiometry of $\sim 8-10 \mathrm{NO}$ molecules, with a clear break point at $\sim 2 \mathrm{NO}$ molecules per cluster, and a less distinct break point at $\sim 6 \mathrm{NO}$ molecules. The absorption spectrum of Fe-S proteins is broad, consisting of overlapping transitions. CD spectroscopy can resolve these transitions, allowing the local cluster environment to be probed. Plots of CD intensity as a function of $\mathrm{NO}$ clearly demonstrated the formation of an intermediate at $2 \mathrm{NO}$ (with an intense CD band at (+)330 nm) (Figure 10), which subsequently reacted with further NO to give less distinct intermediates at $\sim 4$ and $\sim 6 \mathrm{NO}$, with the CD response essentially complete by $\sim 8 \mathrm{NO}$, as for absorbance measurements. Similar CD experiments with [4Fe$4 S$ ] bound to a $23 \mathrm{bp}$ oligonucleotide containing the $h m p 1 A$ promoter revealed that the major features of the NO response were the same as in the absence of DNA; minor differences were observed at higher ratios of NO, such that the less distinct intermediate at $\sim 4 \mathrm{NO}$ was not detected. Taken together, the titrations suggest a series of intermediates at $\sim 2,4$ and $\sim 6 \mathrm{NO}$ per cluster are formed along the nitrosylation pathway. The nature of these intermediate species remains to be determined.

Rapid reaction kinetic experiments (performed with data acquisition at $360 \mathrm{~nm}$ and 420 $\mathrm{nm}$ ) revealed a rapid, complex multi-phased reaction (Figure 10) that was modelled most simply as a five step reaction [68]. The rate of the first step was first order with respect to NO concentration and most likely corresponds to binding of the first $\mathrm{NO}$ to the [4Fe-4S] cluster. Its associated second order rate constant is $k=4.5 \times 10^{6} \mathrm{M}^{-1} \mathrm{~s}^{-1}$, an order of magnitude higher than any other regulator characterised thus far (see below). At higher concentrations of NO $(\geq 100 \mu \mathrm{M})$, the rate became independent of $\mathrm{NO}$, indicating that the rate limiting step does not involve NO under these conditions. Here, it is likely to correspond to the dissociation of the cluster ligand at the unique iron site (a first order process, $k=\sim 600 \mathrm{~s}^{-1}$ ) [68]. All subsequent steps were also found to be first order with respect to NO (at least at low NO concentrations), indicative of the involvement of single NO molecules or the independent binding of NO to more than one iron atom of the cluster. At low [NO]:[Fe-S] ratios, only the early phases of the reaction were observed. This is consistent with there being sufficient NO to achieve the formation of only the first intermediates of the reaction, but insufficient to achieve the final stable product. It also supports the conclusion that NsrR cluster nitrosylation is not a concerted reaction. Hence the second step may represent the binding of a second NO, leading to the generation of an intermediate with clear spectroscopic characteristics, and which may be the species modulating DNA binding to $h m p A 2$. However, we note that it is difficult to assign the identity of this species and those resulting from subsequent steps of the reaction from single wavelength kinetics alone.

Recently, nuclear resonance vibrational spectroscopy (NRVS), utilising ${ }^{32} \mathrm{~S} /{ }^{34} \mathrm{~S}$ and ${ }^{14} \mathrm{NO} /{ }^{15} \mathrm{NO}$ isotopic substitutions, together with density functional theory (DFT) calculations, was used to probe experimental and theoretical responses of [4Fe-4S] NsrR to NO [47] (Figures 9 and 10). While the data did not reveal the nature of the reaction intermediates, it was demonstrated that the nitrosylation reaction does not result in a single iron-nitrosyl product, but rather a mixture of products containing principally $\mathrm{RRE},\left(\left[\mathrm{Fe}_{2}(\mathrm{NO})_{4}(\mathrm{Cys})_{2}\right]\right)$ and RBS $\left(\left[\mathrm{Fe}_{4}(\mathrm{NO})_{7} \mathrm{~S}_{3}\right]\right)$-types species, together with smaller amounts of EPR active DNIC $\left(\left[\mathrm{Fe}_{2}(\mathrm{NO})_{2}(\mathrm{Cys})_{2}\right]\right)$, consistent with EPR studies that showed DNIC accounted for $\sim 16 \%$ of total iron (Figure 10) $[47,68]$. Importantly, the ${ }^{32} \mathrm{~S} /{ }^{34} \mathrm{~S}$ isotope shift data from samples specifically labelled at the cluster sulfides, together with DFT calculations, showed that the RBS-type species cannot be RBS itself because ${ }^{32} S /{ }^{34} S$ shifts in the Fe-S region of the NRVS were not observed, ruling out a primarily sulfide-bridged species (Figure 10). DFT calculations indicated that a Roussin's Red Ester (RRE)-type species, in which one or more of the sulfide bridges of RBS are replaced by thiolate bridges, may be formed in the reaction. This species is predicted to have an NRVS spectrum similar to RBS, but importantly with small or no shifts due to the ${ }^{32} \mathrm{~S} /{ }^{34} \mathrm{~S}$ isotope substitution. DFT calculations also indicated that Cys persulfide forms of these iron-nitrosyls could be present because their calculated NRVS spectra are not significantly different from the Cys thiolate forms [47]. 
Overall, the intermediates of cluster nitrosylation, particularly that detected at an [NO]:[FeS] ratio of 2, correlate well with DNA-binding behaviour, pointing to them being physiologically relevant (Figure 11). Further investigations will be needed to try and establish the precise nature of these nitrosylation intermediates and their physiological significance. Overall, data on $\mathrm{S}$. coelicolor NsrR are consistent with the idea that NsrR acts as a primary NO sensor, coordinating the expression of $h m p A 1 / 2$ as the first line of defence against NO. While kinetic analyses of NsrR and WhiD (see below) predict that NO would preferentially react with NsrR in the $S$. coelicolor cytoplasm containing both NsrR and WhiD, caution is required because there are other components of the $S$. coelicolor cytoplasm that are capable of sensing NO (e.g. DosRS).

\section{$<$ Figure 11 here $>$}

\subsection{Fumarate nitrate reduction (FNR) regulator}

\subsubsection{FNR - a master regulator of the anerobic-aerobic respiratory switch}

Many bacterial species, including the model organism Escherichia coli, are capable of growth on a variety of substrates under varying oxygen tensions. In the absence of $\mathrm{O}_{2}$, alternative electron acceptors, such as fumarate or nitrate, are utilized to support growth, although they are less efficient than aerobic respiration. Hence, the ability to monitor the availability of $\mathrm{O}_{2}$ and to respond by re-programming of gene expression is necessary for these bacteria to remain competitive.

In E. coli, and many other bacteria, the $\mathrm{O}_{2}$-sensing Fumarate and Nitrate Reduction (FNR) protein is the master regulator of the switch between aerobic and anaerobic metabolism. The first crystal structure of dimeric holo-FNR, from Aliivibrio fischeri, was recently reported [133]. Like other members of the cAMP receptor protein (CRP) superfamily, AfFNR consists of two distinct domains, providing sensory and DNA-binding functions, respectively, linked by a dimer interface, see Figure 12. The $\mathrm{N}$-terminal sensory domain contains four essential cysteine residues (Cys20, 23, 29 and 122) that are capable of binding either a $[4 \mathrm{Fe}-4 \mathrm{~S}]^{2+}$ or a $[2 \mathrm{Fe}-2 \mathrm{~S}]^{2+}$ cluster. The $\mathrm{C}$-terminal DNA-binding domain recognizes specific FNR-binding sequences within target promoters. In the absence of $\mathrm{O}_{2}$, monomeric $(\sim 30 \mathrm{kDa})$ FNR acquires a [4Fe-4S] ${ }^{2+}$ cluster, via the iron-sulfur cluster (Isc) machinery, triggering a conformational change at the dimerization interface that leads to the formation of homodimers $(\sim 60 \mathrm{kDa})$ and site specific DNA binding. Kiley and colleagues established that the $[4 \mathrm{Fe}-4 \mathrm{~S}]^{2+} \mathrm{FNR}$ is converted into a $[2 \mathrm{Fe}-2 \mathrm{~S}]^{2+}$ form, both in vivo and in vitro, and that this results in a rearrangement of the dimer interface, leading to monomerization and loss of DNA binding. This cluster conversion process can be described by a simple two step mechanism in which a single electron oxidation of the cluster results in the loss of $\mathrm{Fe}^{2+}$ and formation of a $[3 \mathrm{Fe}-4 \mathrm{~S}]^{1+}$ intermediate, along with $\mathrm{O}_{2}{ }^{-*}$ (step 1), followed by further loss of iron and of sulfide from the $[3 \mathrm{Fe}-4 \mathrm{~S}]^{1+}$ intermediate to yield the $[2 \mathrm{Fe}-2 \mathrm{~S}]^{2+}$ form (step 2) $[4,134-139]$. More recent work has shown the process to be more complex, involving a two electron oxidation of at least some of the cluster sulfide to form sulfane $\left(\mathrm{S}^{0}\right)$, that can react with cysteine side chains $\left(\mathrm{RS}^{-}\right)$ to form persulfide (RSS-). The latter can serve as ligands to the [2Fe-2S] cluster, as recently shown by resonance Raman [140]. However, an in-depth discussion of oxygen induced cluster conversion is beyond the scope of this chapter, but we refer the interested reader to the following references $[4,134-146]$ :

$<$ Figure 12 here>

\subsubsection{FNR functions in response to NO}

Under anaerobic conditions, nitrogen oxides, such as nitrate or nitrite can be utilized as terminal electron acceptors in place of $\mathrm{O}_{2}$. In this respect, we note that NarG represents the most important source of endogenously derived NO during nitrate/nitrate respiration [17]. In vivo, several transcriptional regulators respond to NO. As discussed above, in E.coli the principal regulators are NorR and NsrR. Amongst the genes regulated by NsrR are hmp and hcp. Hmp functions primarily as an $\mathrm{O}_{2}$-dependent $\mathrm{NO}$ dioxygenase, consistent with it being 
repressed under anaerobic conditions by FNR. However, it is capable of catalysing the reduction of $\mathrm{NO}$ to $\mathrm{N}_{2} \mathrm{O}$ under anaerobic conditions, suggesting it plays a minor role in anaerobic NO metabolism and detoxification [65, 147]. In contrast, Hcp expression is strongly induced under anaerobic conditions by FNR and is repressed by NsrR, consistent with its role as an NO reductase. Hcp is discussed in more detail later on because it is an Fe-S cluster protein that reacts with NO in a thus far unique way [148].

Anaerobic exposure of E.coli to physiologically relevant concentrations of $\mathrm{NO}$ led to up-regulation of multiple FNR-repressed genes (including $h m p$ ) and down regulation of FNRactivated genes (including narG), suggesting that NO inactivates FNR in vivo [114]. This was confirmed recently through studies of in vivo transcription from a semisynthetic FNRdependent promoter, where addition of exogenous $N O$ to $E$. coli cultures resulted in a $\sim 4$ fold decrease in FNR-dependent transcription during the first $15 \mathrm{~min}$. A more rapid response ( 3 fold decrease during the first $5 \mathrm{~min}$ ) was observed when cultures were supplemented with nitrite, a source of endogenous $\mathrm{NO}$ [67]. The response of the in vivo system to $\mathrm{O}_{2}$ was initially similar ( 4 fold decrease after $5 \mathrm{~min}$ ) to that of nitrite but more pronounced after $15 \mathrm{~min}$. Overall, FNR-dependent transcription responded to both exogenous and endogenous sources of $\mathrm{NO}$, but was $\sim 4$ fold lower in its response compared to that observed for $\mathrm{O}_{2}$, suggesting FNR is partially protected in the cytoplasm, most likely by the actions initiated by NorR and/or NsrR.

\subsubsection{Nitrosylation of [4Fe-4S] FNR}

In vitro studies revealed that the addition of $4-5 \mathrm{NO}$ molecules resulted in loss of [4Fe-4S] FNR CD intensity, but that $\sim 8 \mathrm{NO}$ molecules were required for the complete nitrosylation reaction, as monitored by absorbance. Nitrosylation resulted in monomerization of the protein, consistent with a significantly reduced DNA binding affinity following NO exposure [67]. Stopped-flow kinetics showed that nitrosylation of the cluster proceeds rapidly, via a multiphasic reaction similar to that described above for NsrR, but with one less clear kinetic phase [67]. The apparent second order rate constant for the first step, which again corresponds to the binding of the first NO to the cluster, was found to be $k=2.8 \times 10^{5} \mathrm{M}^{-1} \mathrm{~s}^{-1}$, and was first order with respect to $\mathrm{NO}$ at all concentrations (up to $\sim 1 \mathrm{mM}$ ). One possibility that would account for why the reaction is slower than that for NsrR and NO-dependent at all NO concentrations is that dissociation of one of the cluster coordinating Cys ligands is not required for the initial $\mathrm{NO}$ binding event. As for NsrR, all subsequent steps were also found to be $\mathrm{NO}$ dependent, again indicating the involvement of a single NO, or the independent binding of NO to more than one iron atom of the cluster. The third kinetic phase of the reaction (referred to as step 3) was characterised by a major decrease in $A_{420 \mathrm{~nm}}$, suggesting significant disruption of the iron-sulfide and/or iron-cysteine bonding, which give rise to the cluster absorbance and CD spectrum. The formation of iron-nitrosyl species requires electrons to form the $\left\{\mathrm{Fe}(\mathrm{NO})_{2}\right\}^{9}$ units of DNIC and RRE/RBS-type species (see section 3). One possibility is that loss of iron-sulfur bonding interactions is due to oxidation of $\mathrm{S}^{2-}$ to $\mathrm{S}^{0}$, with formation of cysteine persulfides, which was shown to occur by mass spectrometry [67, 140], and with the resulting electrons going towards iron-nitrosyl formation.

\subsubsection{FNR - a last line of defence against NO toxicity?}

FNR is known to regulate the aerobic-anaerobic switch via its sensitivity towards $\mathrm{O}_{2}$; so what, then, is the biological significance of its reactivity towards NO in E. coli? It is proposed that if the dedicated NO detoxification systems, Hcp and NorVW, are unable to lower the NO concentration sufficiently to counteract the ensuing nitrosative stress, FNR will become nitrosylated, leading to lowered expression of the nar, nir, nrf and nap operons (which are the major source of endogenously generated $\mathrm{NO}$ and require [4Fe-4S] FNR for activation) and de-repression of $h m p$ expression. We note that Hcp, by virtue of its iron-sulfur clusters, is susceptible to nitrosylation at elevated NO levels, although the physiological concentration of $\mathrm{NO}$ has been hotly contested. In E. coli under anaerobic conditions, in the presence of nitrate, $\mathrm{NO}$ appears to be maintained well below $1 \mu \mathrm{M}$ [148]. The activation of NorR occurs at an NO concentration approximately 10 -fold higher than the NO induced de-repression of NsrR 
controlled genes, such as hcp [148]. Moreover, FNR-dependent expression drops significantly at extracellular concentrations of $\geq 5 \mu \mathrm{M}$, suggesting an upper limit for the detoxifying capacity of the first line detoxification systems [65]. Thus, the nitrosylation of FNR would only occur when the cellular detoxification systems are overwhelmed. This results not only in the anaerobic expression of $h m p$, but probably more importantly, the shutdown of nar, nir, nrf and nap operon expression and consequently endogenous NO production. This implies that FNR functions as a final safe guard against $\mathrm{NO}$ damage in a hierarchal network that has evolved to monitor, and respond effectively to, both endogenously and exogenously generated NO.

\subsection{FnrP}

The Paracoccus denitrificans orthologue of FNR, FnrP, also binds a [4Fe-4S] cluster but has a different arrangement of cysteine residues at its $\mathrm{N}$-terminus [149]. FnrP undergoes $\mathrm{O}_{2}$ driven cluster conversion analogous to E.coli FNR, but at a rate approximately six fold lower than FNR. This suggests that FnrP remains transcriptionally active at higher $\mathrm{O}_{2}$ tensions than $E$. coli FNR, consistent with a role for FnrP in activating expression of the high $\mathrm{O}_{2}$ affinity cytochrome $c$ oxidase ( $c c 0)$ in $P$. denitrificans under micro-aerobic conditions [150]. There is also increasing evidence to suggest that FnrP, like E.coli FNR, responds to NO in vivo [150, 151], and in vitro studies of its reaction with NO revealed significant similarities with the FNR nitrosylation reaction described above: the reaction involved multiple $\mathrm{NO}$ molecules and resulted in dissociation of the FnrP dimer into monomers, with concomitant loss of DNA binding [132].

In P. denitrificans, three principal NO-sensing regulators, NsrR, NnrR and FnrP, coordinate gene regulation. In other bacterial species, NsrR regulates genes involved in detoxification of NO, such as $h m p$ (see Section 4.2). NnrR principally activates the expression of nitrite, NO, and nitrous oxide reductases under anaerobic conditions in response to NO, thereby facilitating denitrification [152]. With regard to denitrification, FnrP co-regulates the expression of nitrate and nitrous oxide reductases, ensuring their production under semiaerobic conditions [151]. We also note that $P$. denitrificans lacks an $h c p$ gene [153]. Hence, FnrP may be more susceptible than E.coli FNR to nitrosylation by endogenous NO, leading to lowered expression of $c c 0$, and modulation of the nar and nos operons (which are activated for expression by [4Fe-4S] FnrP). The concomitant detection of $\mathrm{NO}$ by NnrR would then ensure the timely expression of the nir, nor, and nos operons [132, 151], minimizing transitory nitrosative stress as metabolic modes are switched over in favor of denitrification.

\subsection{WhiB-like (Wbl) family proteins}

\subsubsection{A [4Fe-4S] cluster-containing regulatory protein family of the Actinomycetes}

The WhiB-like family of regulators were discovered through the study of white (whi) Streptomyces coelicolor mutants that failed to produce the usual grey spore pigment and were arrested at different developmental stages of sporulation. Homologues of the founding member, S. coelicolor WhiB, are confined to Actinobacteria; a phylum of Gram-positive bacteria that includes Streptomyces, the most abundant source of clinically important antibiotics; Bifidobacterium, a component of the human gastro-intestinal and probiotic, as well as important human pathogens such as Mycobacterium tuberculosis and Corynebcterium diphtheria [154-157]. Wbl proteins are generally small $(\sim 9-15 \mathrm{kDa})$ and contain a highly conserved pattern of cysteine residues Cys- $X_{n}-$ Cys- $X_{2}-$ Cys- $X_{5}-C y s$ that bind a [4Fe-4S] cluster, at least where this has been investigated [156]. The function of Wbl protein has been the subject of some controversy. They were initially believed to be regulatory proteins, with proposed similarities to the Fe-S regulators discussed above in terms of the sensitivity of their Fe-S clusters to reactive oxygen species (ROS), reactive nitrogen species (RNS), or cellular redox balance. However, in vitro evidence of DNA binding proved elusive. Meanwhile, cluster-free Wbl proteins were shown to exhibit protein disulfide reductase activity, leading to the proposal that loss of the Fe-S cluster through oxidative stress causes the activation of Wbl proteins as difulfide reductases [158-160]. However, it seems unlikely that this is a general property of $\mathrm{Wbl}$ proteins as similar investigations with other $\mathrm{Wbl}$ proteins failed to detect any general reductase activity $[40,161]$. It is possible that Wbl proteins may act only on specific 
cellular targets. M. tuberculosis WhiB1 was reported to participate in a specific disulfide mediate interaction with the alpha $(1,4)$-glucan branching enzyme (GlgB) [162], whilst WhiB2 was reported to act like a chaperone, suppressing the aggregation of several model substrates [163]. However, the majority of more recent evidence now indicates that $\mathrm{Wbl}$ proteins are indeed DNA regulatory proteins that utilize their Fe-S cluster as a sensory unit that directly or indirectly modulates DNA-binding[40, 164-167].

\subsubsection{Wbl proteins in Mycobacteria}

In M. tuberculosis, Wbl proteins are involved in the pathogen's remarkable ability to persist for long periods of time with in its host (including the macrophage phagosome), as well as its innate resistance to a wide range of antibiotics. In vivo, $M$. tuberculosis WhiB1 is essential for survival, and is regulated by CRP in response to cAMP $[40,168]$. WhiB1 regulates its own expression and that of the essential chaperonin encoding groEL2 by binding to its promoter sequence in the cluster-free apo-form. WhiB1 acts to oppose the Cmr (Rv1675c) mediated, but cAMP-independent, activation of groEL2 expression [169]. WhiB2 is important for correct septation and cell division, and in the case of $M$. smegmatis, can be replaced with $M$. tuberculosis WhiB2 or S. coelicolor WhiB, implying that these Wbl proteins are functionally equivalent $[170,171]$. In this respect, it is noteworthy that mycobacteriophage TM4 carries its own WhiB2 orthologue, WhiBTM4, which recognizes the host whiB2 promoter and that expression of WhiBTM4 in a mycobacterial host hindered septation, similar to a $\Delta$ whiB2 phenotype [164].

From a physiological perspective, $M$. tuberculosis WhiB3 is perhaps the best understood of all the Wbl proteins. In vivo, whiB3 expression is upregulated in response to NO and an acidic extracellular $\mathrm{pH}$. Seminal work by Singh et al [172] showed that [4Fe-4S] WhiB3 was sensitive to NO, with exposure enhancing site specific DNA binding and, in vivo, shifting propionate anabolism in favor of virulence determinants (polyketides, polyacyltrehaloses, sulfolipids, and phthiocerol dimycocerosates) and storage lipids (principally triacylglycerol) [172-174]. Remarkably, the WhiB3-dependent production of polyketide virulence determinants, in part, disrupts phagosomal maturation and acidification. Recent work showed that it also plays an important role in resistance to acidic stress in the phagosome by regulating genes involved in lipid anabolism, secretion and redox metabolism. Connected to the latter point, Saini et al [175] have reported that WhiB3 also regulates the production of ergothioneine, a factor critical for the survival for $M$. tuberculosis inside macrophage phagosomes. Mycothiol (MSH), together with ergothioneine (EGT), form the principal redox buffer systems of Mycobacteria and play an essential role in virulence [175, 176]. Remarkably, WhiB3 appears to block phagosomal maturation through the regulation of polyketide lipid production [177].

WhiB4 - 5 have, in general, received less attention, although WhiB4 appears to control the oxidative response of $M$. tuberculosis, directly regulating alkyl hydroperoxidase (aphC), an $\mathrm{NADH}$-dependent peroxidase and peroxynitrite reductase system [178, 179]. WhiB5 appears to be important for the reactivation of dormant $M$. tuberculosis [165]. WhiB6 is strongly upregulated in response to stress agents (e.g. heat, diamide, NO, cumene peroxide)[155, 180]. Recently, Steyn and colleagues showed that WhiB6 from M. marinum (closely related to $M$. tuberculosis) differentially regulates the DosR dormancy and the ESX-1 virulence factor regulons through its ability to sense $\mathrm{NO}$ and oxidative stress via its Fe-S cluster [39]. This led them to propose a model for the function of WhiB6 in which it is upregulated by NO when $M$. marinum is engulfed by activated macrophages. WhiB6 promotes the expression of the ESX1 regulon which exports virulence factors that enable the bacterium to survive in the macrophage by escaping the phagosome. At the same time [4Fe-4S] WhiB6, via ESX-1, enhances recruitment of macrophages to the granulomas formed, increasing the scope of infection. Sustained exposure to exogenous ROS and RNS from the host's immune system leads to apo- and nitrsoylated forms of WhiB6, which promote a shift away from aerobic respiration and into dormancy, via the DosR/S/T system, enabling $M$. marinum to establish a persistant infection within the granulomas. Finally, the well documented WhiB7 regulates 
aspects of innate resistance, including export and inactivation, to a variety therapeutic antibiotics [181-183].

\subsubsection{Wbl proteins in Streptomyces coelicolor}

Streptomyces coelicolor encodes $11 \mathrm{Wbl}$ proteins of which five, WbIE (WhiB1), WhiB (WhiB2), WhiD (WhiB3), WblA (WhiB4) and WbIC (WhiB7) are well conserved in other actinobacteria species. WhiB is required for the initiation of sporulation and septation. Elegant work by Bush et al [167] recently showed that WhiB does not act independently, but rather requires an unusual partner, WhiA; a transcription factor derived from a homing endonuclease. Together WhiA and WhiB control a regulon of sporulation genes. Substitution of Fe-S cluster coordinating cysteine residues in WhiB was sufficient to prevent DNA binding by both WhiA and $\mathrm{WhiB}$ in vivo. Both WbIE and WbIA play a role in the development of Streptomyces, but have been little studied. We note that WblE could not be disrupted suggesting it is essential, like WhiB1, and WbIA appears play a regulator role in antibiotic biosynthesis [184]. Based on phenotypic analysis, WhiD is required for the late stages of sporulation, whereas, disruption of $w b / C$ lead to mutants that were hypersensitive to antibiotics, as observed for $M$. tuberculosis whiB7 mutants [185, 186]. Recent work by Yoo et al [187] showed that WblC (WhiB7) induces a stable isoform of the ECF sigma $(\sigma)$ factor $R$ that governs thiol-oxidative stress, and, that WbIC binding to the sigRp1 promoter responds to antibiotic treatment in vivo. A similar phenomenon appears to exist in $M$. tuberculosis, suggesting an important role for WblC/WhiB7 in innate antibiotic resistance [187].

\subsubsection{Reaction of Wbl protein [4Fe-4S] clusters with NO}

M. tuberculosis WhiB1 and S. coelicolor WhiD were the first Fe-S cluster regulators to have their reactions with $\mathrm{NO}$ examined in detail using spectroscopic and/or rapid reaction kinetic methods $[40,41]$. These studies revealed for the first time the rapid multi-NO ( 8 per cluster), multi-phasic reaction that now characterizes these proteins. The first step of the reaction was, as subsequently found for other Fe-S cluster regulators, first order with respect to NO, with an apparent second-order rate constant of $k=\sim 6 \times 10^{5} \mathrm{M}^{-1} \mathrm{~s}^{-1}$. All subsequent steps were also first order in NO. Overall, WhiD is more sensitive than FNR (which has a secondary role in NO sensing, Section 4.3) and only marginally less sensitive than NsrR, a front line NO sensor from the same organism (see Section 4.2). Furthermore, its reaction is more similar to that of FNR than NsrR, particularly in that no stable intermediates were detected. These in vitro observations are consistent with a function in sensing NO in vivo, particularly when the fact that the $\mathrm{NO}$ reaction of $\mathrm{Wbl}$ proteins is $\sim 10^{4}$-fold faster than the reaction with $\mathrm{O}_{2}$. $[41,180]$.

NRVS studies of WhiD showed that multiple iron-nitrosyl species, principally of the RRE- and RBS-types, are formed. As for NsrR, RBS itself cannot be a product due to the absence of ${ }^{32} \mathrm{~S} /{ }^{34} \mathrm{~S}$ isotopic shifts in the NRVS spectrum of nitrosylated WhiD, and a RRE-type species may instead be present. From the NRVS, there was a smaller component of RRE compared to in the NsrR spectrum, and significantly less DNIC present. This is consistent with EPR studies that showed that DNIC accounted for only 3\% of the total initial cluster iron [41, 47].

Overall, it is now becoming clear that the reaction of NO with some of the Wbl proteins is a central signaling process and that the iron-sulfur cluster plays a key functional role in controlling DNA-binding.

\subsection{SoxRS}

\subsubsection{SoxRS, a regulator of redox stress}

Bacteria are exposed to a multitude of redox active molecules that may serve as quorum signals, virulence factors or antibiotics. Many of these compounds are produced to help bacteria commandeer resources and/or gain an edge over competing species, while others are man-made. The herbicide methyl-viologen (Paraquat) is an example of the latter. In biological systems methyl-viologen is capable of redox cycling with two potentially important consequences. Firstly, it can abstract an electron from $\mathrm{NAD}(\mathrm{P}) \mathrm{H}$-reduced flavin cofactors, leading to the generation of a methyl-viologen radical cation, and the depletion of cellular 
$\mathrm{NAD}(\mathrm{P}) \mathrm{H}$. Secondly, reduced methyl-viologen will rapidly react with $\mathrm{O}_{2}$, generating reactive oxygen species such as $\mathrm{O}_{2}{ }^{-*}$ and/or $\mathrm{H}_{2} \mathrm{O}_{2}$ [188].

The Escherichia coli SoxRS system constitutes an unusual two-part regulatory system in which the two proteins act sequentially to activate gene transcription in response to stresses generated by redox active molecules, such as, but not limited to, methyl-viologen. For a long period of time it was believed that SoxRS activation resulted from the capacity of such molecules to generate superoxide in vivo. SoxR, which belongs to the MerR family of metalresponsive transcriptional regulators, exists as a homodimer in solution, containing one [2Fe2S] per monomer. Although the cluster is not required for structural stability or DNA binding, mutagenesis of the cluster coordinating cysteine residues showed that $\mathrm{C} 119, \mathrm{C} 122, \mathrm{C} 124$, $\mathrm{C} 130$ and the [2Fe-2S] cluster is essential for in vivo activation of soxS transcription; the only well-established target for SoxR. The SoxS protein, also a transcriptional activator, switches on the expression of $>30$ genes, including a Mn-superoxide dismutase, multi drug efflux systems, a suit of multiple antibiotic resistance (MarR) like transcriptional regulators, and makes adjustments to metabolism in favor of $\operatorname{NAD}(\mathrm{P}) \mathrm{H}$ regeneration. SoxS is also subject to rapid proteolytic degradation, thus ensuring the system response remains dependent on the signal sensed by SoxR [115, 116, 189, 190]].

\subsection{2. [2Fe-2S] SoxR}

$\mathrm{X}$-ray structures of [2Fe-2S] SoxR in the free form and in complex with soxS promoter DNA are available, see Figure 13. The overall architecture of SoxR is similar to other MerR family members, although significant differences exist in the alignment of the dimerization helix with the DNA-binding domain. In comparison to other structurally characterized [2Fe-2S] clusters, the SoxR cluster is solvent exposed, held in an asymmetric electrostatic environment, with the rhomb plane of the cluster tilted $\sim 20^{\circ}$ relative to the plane of coordinating cysteine residues. Furthermore, the cluster is partially stabilized through interactions with residues belonging to the other monomer of the dimer, including a number within the DNA-binding domain [191].

\section{<Figure 13 here $>$}

The [2Fe-2S] cluster can exist in +1 and +2 states, connected by a reduction potential of $-285 \mathrm{mV}$ (versus SHE at $\mathrm{pH} 7.6$ ). Indeed, SoxR is readily isolated with a [2Fe-2S] ${ }^{+}$cluster, and is maintained in the reduced state, in vivo, by the resC and rSXABCDGE system at the expense of $\mathrm{NAD}(\mathrm{P}) \mathrm{H}$ [192]. Only when the cluster is in the [2Fe-2S] ${ }^{2+}$ form can SoxR activate soxS transcription by remodeling of the -35 and -10 promoter elements such that they become optimally positioned for interaction with RNA polymerase. Whether DNA-binding has an important effect on the redox properties of the cluster is controversial. Electrochemical measurements on DNA-modified electrodes revealed a dramatic shift in the reduction potential to $+200 \mathrm{mV}$ for SoxR bound to its cognate DNA [193], while more recent solution equilibrium experiments indicated a small decrease in the potential for the DNA-bound form compared to free in solution [194].

Despite this uncertainty, the question of how a redox change translates into the conformational changes required to activate transcription remains. The answer appears to lie with the asymmetric electrostatic environment surrounding the cluster. It is suggested that in the reduced +1 state the additional negative charge attracts the main chain amides towards the sulfur atoms of the cluster and repels close lying oxygen atoms, while oxidation of the cluster to the +2 state increases attraction to negatively charged carbonyl oxygen atoms. These subtle changes to the cluster binding domain lead to substantial change in the relative position of the DNA-binding domains, widening the distance between the recognition helices to accommodate the unusually long, 19bp, spacer between the -35 and -10 elements of the soxS promoter [191].

Recently, it was shown that redox-cycling molecules are toxic to $E$. coli even in the absence of $\mathrm{O}_{2}$, suggesting $\mathrm{O}_{2} \cdot{ }^{-*}$ production is not exclusively responsible for the activation of SoxRS [190, 195]. Moreover, changes in the intracellular NAD $(P) H / N A D(P)$ ratio also result in the activation of SoxRS[196-198]. We note that the solvent exposed nature of [2Fe-2S] cluster 
likely enables rapid electron transfer to and from the cluster. Indeed, it would appear that oxidation of the $[2 \mathrm{Fe}-2 \mathrm{~S}]^{1+}$ cluster of SoxR can be catalyzed directly by redox-cycling molecules, such as methyl-viologen [195]

Although SoxR is widely distributed among bacteria, SoxS is absent in non-enteric species, such as Streptomyces coelicolor [199]. Hence, in these species SoxR directly regulates the expression of target genes. Interestingly, S. coelicolor SoxR (ScSoxR) can also be activated by small redox active molecules [190, 199]. We note that ScSoxR $(-185 \mathrm{mV})$ has a higher redox potential than E. coli SoxR $(-285 \mathrm{mV})$ and that Lee et al have shown that two amino acid residues appear to be critical for tuning the redox potential of the [2Fe-2S] cluster. As such it was possible to change the sensitivity profile of EcSoxR (R127L/P131V, -192 mV) to resemble that of ScSoxR, and vice versa for ScSoxR (L126R/V130P, -273 mV). The higher redox potential of $S c S o x R$ results the detection of a slightly narrower range of redox active molecules, reflecting its increased sensitivity to extracellular actinorhodin (an antibiotic synthesized by $S$. coelicolor) and limited response to methyl viologen [190, 200].

\subsubsection{Sensitivity of [2Fe-2S] SoxR to NO}

It has been known for some time that SoxR-dependent activation of soxS can also be stimulated by NO in vivo [201, 202]. More recently, Singh et al reexamined the in vivo effect of NO-generating compounds on SoxR proteins. They found that EcSoxR was activated by all of the NO-generating compounds (SNP, DETA-NO and GSNO) tested, but somewhat surprisingly, ScSoxR was unresponsive[190].. We note in some cases exogenous NO sources may not accumulate in the cytoplasm, possibly due to the protective effects of NsrR [108]

Exposure of [2Fe-2S] SoxR to NO leads to the formation of a $\mathrm{g}=2.03 \mathrm{EPR}$ signal indicative of at least some DNIC formation[202]. The kinetics of this reaction, recently reported by Fujikawa et al [203], were explored using pulse radiolysis of nitrite solutions to generate NO. The reaction was found to be extremely rapid and biphasic in character. The faster phase, which corresponds to the bimolecular reaction of $\mathrm{NO}$ with $[2 \mathrm{Fe}-2 \mathrm{~S}]^{2+}$ cluster, was reported to have a second order rate constant of $k=1.3 \times 10^{8} \mathrm{M}^{-1} \mathrm{~s}^{-1}$, close to diffusion controlled and approx. two orders of magnitude faster than the reaction of NO with $S$. coelicolor NsrR [68, 203]. This is consistent with the solvent exposed location of the cluster. It is suggested that this fast phase correspond to the reaction of one equivalent of NO with the cluster, resulting in a mononitrosyl complex, prior to the addition of a second equivalent of NO, giving a dinitrosyl cluster derivative. While no further reaction was observed using pulse radiolysis, solution experiments indicated that two further equivalents of $\mathrm{NO}$ could be added to the cluster, resulting in the formation of DNIC species $\left[\mathrm{RS}_{2} \mathrm{Fe}(\mathrm{NO})_{2}\right.$ ] [203-205]. Since the nitrosylation of SoxR appears to be an activating event, it is difficult to discount it as a chemical artifact [106].

In this respect, we note that soxS transcription is induced by macrophages and that the SoxRS regulon appears to prolong the survival of $E$. coli in response to activated macrophages. This is modulated by iNOS inhibitors, suggesting that NO activation of SoxR is of physiological significance [201, 206]. However, microarray studies have revealed that the activity of NsrR, NorR (dedicated NO sensors), IscR, Fur, FNR (secondary NO sensors) and SoxR are all modulated by the presence $\mathrm{NO}$ and that the physiological response of the SoxRS appears to be limited in E .coli [114]. For some bacteria, such as Salmonella enterica, soxS is dispensable for virulence/infection and the SoxRS regulon is not significantly utilized in the presence of activated marcophages [207, 208]. The current understanding of the sensing by the SoxRS system is summarized in Figure 14.

$<$ Figure 14 here>

\subsection{Iron regulatory protein 1 (IRP1) and other aconitases}

Aconitase is an enzyme of the citric acid cycle, which is localized in the mitochondrion of eukaryotes. It binds a [4Fe-4S] cluster, which is key to its dehydratase activity in converting citrate to isocitrate. In aconitase, the cluster is coordinated by only three cysteine residues, such that one iron has a vacant coordination site for substrate binding [3]. Thus, the [4Fe-4S] 
cluster is susceptible to losing that iron, generating an enzymatically inactive [3Fe-4S] cluster that can degrade further to the apo-protein.

\subsubsection{Iron regulatory protein 1 (IRP1)}

A close homologue of aconitase is found in the cytoplasm of mammals and is known as cytoplasmic aconitase (c-aconitase) or iron regulatory protein 1 (IRP1), in recognition of its role as a key regulator of cellular iron levels. Under conditions of iron deficiency, IRP1 loses its cluster; in its apo-form, it functions alongside IRP2 (which lacks an iron sulfur cluster but is regulated in an iron-dependent manner via ubiquitin-mediated degradation) to posttranscriptionally regulate the expression of genes involved in iron metabolism by binding to IREs at either the 5' or 3' ends of the mRNA transcripts, which leads to either inhibition (e.g. ferritin) or promotion (e.g. transferrin receptor) of translation (reviewed in [209, 210]. While early studies of mammalian cells lacking IRP1 or IRP2 indicated that IRP2 is the principal sensor of iron, recent studies have revealed that IRP1 plays essential functions in erythropoiesis and in pulmonary and cardiovascular systems [211].

IRP1, by virtue of its iron-sulfur cluster, is also susceptible to nitrosylation, resulting in protein bound DNIC complexes [212]. IRP2 has also been reported to be capable of sensing $\mathrm{NO}$, but the role of IRP1 and IRP2 in the NO-mediated regulation of iron metabolism has remained controversial. Stys et al [213] have shown that in NO exposed mouse macrophages lacking IRP1 or IRP2, IRP1 was entirely responsible for the post transcriptional regulation of heavy and light chain ferritins, ferroportin, and transferrin receptor 1 in response to NO. Following NO treatment IRP1 relieved deficiencies in cells lacking IRP2, resulting in increases in iron uptake, reduced iron sequestration and export. Overall enough intracellular iron was accumulated to facilitate Fe-S cluster biosynthesis and restore the function of mitochondrial aconitase and the citric acid cycle. Thus, while there is still much to learn about the importance of IRP1, it appears to have an important role in mitigating the effects of NO on Fe-S proteins, by ensuring sufficient supply of iron for repair.

\subsubsection{Bacterial aconitases with regulatory roles}

In E.coli, two types of bacterial aconitases have been identified; one is similar to eukaryotic aconitases and is expressed under stress conditions (AcnA; part of the SoxRS operon), while the other is unique to bacteria in that it contains an additional $\mathrm{N}$-terminal domain and a different domain arrangement (AcnB; less stable than AcnA to oxidative stress) and serves as the principal citric acid cycle enzyme [117, 214]. In E. coli AcnA and AcnB are expressed under different conditions and exhibit different stabilities, but both types have been shown to bind to specific sequences in the $3^{\prime}$ untranslated regions of $a c n A$ and acnB mRNA in their cluster-free forms, thereby promoting the production of the aconitase proteins under conditions of stress (eg iron starvation, or oxidative/nitrosative stress) that depletes the cluster-bound enzymatically active form [215, 216]. Interestingly, AcnA enhances the stability of the sodA mRNA transcripts (which is also part of the SoxRS regulon), whereas AcnB lowers sodA transcript stability $[115,216]$. It is suggest that the aconitase proteins of E.coli play a protective role against oxidative stress during aerobic growth by acting as a sink for reactive oxygen species thereby modulating the stability of sodA mRNA transcripts and ultimately SodA synthesis [117].

\subsection{HcpR2 and the hybrid cluster protein (Hcp)}

The so called hybrid cluster protein ( $\mathrm{Hcp}$ ) is found in many anaerobic or facultatively anaerobic bacteria, where it functions in response to nitrosative stress [217-220]. Hcp shares structural homology with anaerobic carbon monoxide dehydrogenases and contain two types of iron sulfur clusters; the first occurs as either a [2Fe-2S] or [4Fe-4S] cluster, while the second, socalled "hybrid cluster", is a unique cluster type, the precise form of which is dependent on the oxidation state. The oxidised form consists of a [4Fe-3O-2S] core with an additional sulfur coordinating as a persulfide, see Figure 15. Upon reduction, significant changes occur, with at least two of the oxygens lost replaced in part by an additional sulfide (from the persulfide) [221-223]. The role Hcp plays in the nitrosoative stress response during anaerobic growth has 
been something of an enigma since its discovery. However, recent work by Wang et al [148] has shown that Hcp functions along with an $\mathrm{NADH}$-dependent reductase, $\mathrm{Hcr}$, as a high affinity $\mathrm{NO}$ reductase that stoichometrically reduces $\mathrm{NO}$ to $\mathrm{N}_{2} \mathrm{O}$. These discoveries led to the proposal that $\mathrm{Hcp}-\mathrm{Hcr}$ is the major NO reductase at very low concentrations of $\mathrm{NO}$ (which are commonly found in the bacterial cytoplasm during the anaerobic reduction of nitrate and nitrite). The mechanism of NO reduction by Hcp remains to be determined.

$<$ Figure 15 here>

In E. coli, hcp is under the regulation of NsrR and FNR, both of which are susceptible to NO inactivation (see Sections 4.2 and 4.3). In sulfate reducing bacteria, hcp expression is regulated by HcpR2, an Fe-S cluster containing member of the CRP/FNR regulatory family that has been shown to be sensitive to $\mathrm{NO}$ and $\mathrm{O}_{2}$ [224].

\section{Perspectives and future directions}

Significant progress has been made in recent years in understanding how organisms respond to NO. It is clear that, in addition to being targets of NO toxicity, Fe-S proteins play a central role in sensing the presence of both toxic and sub-toxic/signalling levels of $\mathrm{NO}$ and in regulating the appropriate cellular response. Undoubtedly, further discoveries are set to be made concerning how NO is sensed and particularly how it functions in signalling. Major progress has been made in understanding how NO-sensing regulatory proteins function, particularly in bacteria, both in terms of the genes they control and also their biochemistry, through the characterisation of the Fe-S cluster reactions with NO. Efforts to characterise iron-nitrosyl intermediates and products have led to the development and application of novel methodologies that can overcome the limitations of existing (traditionally applied) spectroscopies to discriminate between different iron-nitrosyl species. Such approaches are still under development and it is likely that much more progress will be made on this in the next few years. Information on iron-nitrosyl species formed during reaction of Fe-S cluster with NO will enable mechanisms of nitrosylation to be fully elucidated, including the identification of stable and transient intermediates, and will reveal how the DNA-binding affinity of the regulator is affected as nitrosylation proceeds. High resolution structural information of Fe-S and nitrosylated forms will also be needed, and this remains a major challenge for the community.

\section{Acknowledgements}

Our work was supported by the UK's Biotechnology and Biological Sciences Research Council (BBSRC) through grants BB/J003247/1 and BB/L007673/1, and by the Royal Society through the award of a Newton International Fellowship to E.L.D. 


\section{References}

[1] Mettert EL, Kiley PJ. Fe-S proteins that regulate gene expression. Biochim Biophys Acta 2015;1853:12841293.

[2] Beinert H, Holm RH, Munck E. Iron-sulfur clusters: Nature's modular, multipurpose structures. Science 1997;277:653-659.

[3] Beinert H, Kennedy MC, Stout CD. Aconitase as iron-sulfur protein, enzyme, and iron-regulatory protein. Chem Rev 1996;96:2335-2374.

[4] Crack JC, Green J, Cheesman MR, Le Brun NE, Thomson AJ. Superoxide-mediated amplification of the oxygen-induced switch from [4Fe-4S] to [2Fe-2S] clusters in the transcriptional regulator FNR. Proc Natl Acad Sci USA 2007;104:2092-2097.

[5] Shomura Y, Yoon KS, Nishihara H, Higuchi Y. Structural basis for a [4Fe-3S] cluster in the oxygen-tolerant membrane-bound [NiFe]-hydrogenase. Nature 2011;479:253-256.

[6] Peters JW, Stowell MHB, Soltis SM, Finnegan MG, Johnson MK, Rees DC. Redox-dependent structural changes in the nitrogenase P-cluster. Biochemistry 1997;36:1181-1187.

[7] Johnson MK. Iron-sulfur proteins: new roles for old clusters. Curr Opin Chem Biol 1998;2:173-181.

[8] Bak DW, Elliott SJ. Alternative FeS cluster ligands: tuning redox potentials and chemistry. Curr Opin Chem Biol 2014;19:50-58.

[9] Dey A, Jenney FE, Jr., Adams MW, et al. Solvent tuning of electrochemical potentials in the active sites of HiPIP versus ferredoxin. Science 2007;318:1464-1468.

[10] Imlay JA. Iron-sulphur clusters and the problem with oxygen. Mol Microbiol 2006;59:1073-1082.

[11] Wink DA, Mitchell JB. Chemical biology of nitric oxide: Insights into regulatory, cytotoxic, and cytoprotective mechanisms of nitric oxide. Free Rad Biol Med 1998;25:434-456.

[12] Stuehr DJ. Mammalian nitric oxide synthases. Biochim Biophys Acta 1999;1411:217-230.

[13] Krieglstein CF, Cerwinka WH, Laroux FS, et al. Regulation of murine intestinal inflammation by reactive metabolites of oxygen and nitrogen: divergent roles of superoxide and nitric oxide. J Exper Med 2001;194:1207-1218.

[14] Jung JY, Madan-Lala R, Georgieva M, et al. The intracellular environment of human macrophages that produce nitric oxide promotes growth of mycobacteria. Infect Immun 2013;81:3198-3209.

[15] Gobert AP, McGee DJ, Akhtar M, et al. Helicobacter pylori arginase inhibits nitric oxide production by eukaryotic cells: a strategy for bacterial survival. Proc Natl Acad Sci USA 2001;98:13844-13849.

[16] Bogdan C. Nitric oxide synthase in innate and adaptive immunity: an update. Trends Immunol 2015;36:161-178.

[17] Vine CE, Cole JA. Unresolved sources, sinks, and pathways for the recovery of enteric bacteria from nitrosative stress. FEMS Microbiol Lett 2011;325:99-107.

[18] Poole RK. Nitric oxide and nitrosative stress tolerance in bacteria. Biochem Soc Trans 2005;33:176-180.

[19] Seth D, Hausladen A, Wang YJ, Stamler JS. Endogenous protein S-nitrosylation in E. coli: regulation by OxyR. Science 2012;336:470-473.

[20] Spiro S. Metalloregulatory proteins and nitric oxide signalling in bacteria. Biochem Soc Trans 2008;36:1160-1164.

[21] Hill BG, Dranka BP, Bailey SM, Lancaster JR, Jr., Darley-Usmar VM. What part of NO don't you understand? Some answers to the cardinal questions in nitric oxide biology. J Biol Chem 2010;285:1969919704.

[22] Hughes MN. Chemistry of nitric oxide and related species. Meth Enzymol 2008;436:3-19.

[23] McCleverty JA. Chemistry of nitric oxide relevant to biology. Chem Rev 2004;104:403-418.

[24] Malinski T, Taha Z, Grunfeld S, Patton S, Kapturczak M, Tomboulian P. Diffusion of nitric oxide in the aorta wall monitored in situ by porphyrinic microsensors. Biochem Biophys Res Commun 1993;193:10761082.

[25] Lancaster JR, Jr. A tutorial on the diffusibility and reactivity of free nitric oxide. Nitric Oxide 1997;1:18-30.

[26] Bartberger MD, Liu W, Ford E, et al. The reduction potential of nitric oxide (NO) and its importance to NO biochemistry. Proc Natl Acad Sci USA 2002;99:10958-10963.

[27] Stanbury DM. Reduction potentials involving inorganic free radicals in aqueous solution Adv Inorg Chem 1989;33:69.

[28] Heinrich TA, da Silva RS, Miranda KM, Switzer CH, Wink DA, Fukuto JM. Biological nitric oxide signalling: chemistry and terminology. Br J Pharmacol 2013;169:1417-1429.

[29] Huie RE, Padmaja S. The reaction of NO with superoxide. Free Rad Res Commun 1993;18:195-199.

[30] Radi R. Nitric oxide, oxidants, and protein tyrosine nitration. Proc Natl Acad Sci USA 2004;101:4003-4008.

[31] Lundberg JO, Weitzberg E, Gladwin MT. The nitrate-nitrite-nitric oxide pathway in physiology and therapeutics. Nat Rev Drug Discov 2008;7:156-167.

[32] Hagen T, Taylor CT, Lam F, Moncada S. Redistribution of intracellular oxygen in hypoxia by nitric oxide: effect on HIF1alpha. Science 2003;302:1975-1978.

[33] Gould N, Doulias PT, Tenopoulou M, Raju K, Ischiropoulos H. Regulation of protein function and signaling by reversible cysteine S-nitrosylation. J Biol Chem 2013;288:26473-26479.

[34] Smith BC, Marletta MA. Mechanisms of S-nitrosothiol formation and selectivity in nitric oxide signaling. Curr Opin Chem Biol 2012;16:498-506.

[35] Knowles RG, Palacios M, Palmer RM, Moncada S. Formation of nitric oxide from L-arginine in the central nervous system: a transduction mechanism for stimulation of the soluble guanylate cyclase. Proc Natl Acad Sci USA 1989;86:5159-5162. 
[36] Howard-Flanders P. Effect of nitric oxide on the radiosensitivity of bacteria. Nature 1957;180:1191-1192.

[37] Crack JC, Green J, Thomson AJ, Le Brun NE. Iron-sulfur clusters as biological sensors: the chemistry of reactions with molecular oxygen and nitric oxide. Acc Chem Res 2014;47:3196-3205.

[38] Nisbett LM, Boon EM. Nitric Oxide Regulation of H-NOX Signaling Pathways in Bacteria. Biochemistry 2016;55:4873-4884.

[39] Chen Z, Hu Y, Cumming BM, et al. Mycobacterial WhiB6 Differentially Regulates ESX-1 and the Dos Regulon to Modulate Granuloma Formation and Virulence in Zebrafish. Cell Rep 2016;16:2512-2524.

[40] Smith LJ, Stapleton MR, Fullstone GJ, et al. Mycobacterium tuberculosis WhiB1 is an essential DNAbinding protein with a nitric oxide-sensitive iron-sulfur cluster. Biochem J 2010;432:417-427.

[41] Crack JC, Smith LJ, Stapleton MR, et al. Mechanistic insight into the nitrosylation of the [4Fe-4S] cluster of WhiB-like proteins. J Am Chem Soc 2011;133:1112-1121.

[42] Frolov EN, Vanin AF. New type of paramagnetic nitrosyl complexes of non-heme iron. Biofizika 1973;18:605-610.

[43] Mallard JR, Kent M. Differences observed between electron spin resonance signals from surviving tumour tissues and from their corresponding normal tissues. Nature 1964;204:1192.

[44] Vanin AF, Nalbandian RM. Free Radicals of a New Type in Yeast Cells. Biofizika 1965;10:167-168.

[45] Tinberg CE, Tonzetich ZJ, Wang H, et al. Characterization of iron dinitrosyl species formed in the reaction of nitric oxide with a biological Rieske center. J Am Chem Soc 2010;132:18168-18176.

[46] Tonzetich ZJ, Wang H, Mitra D, et al. Identification of protein-bound dinitrosyl iron complexes by nuclear resonance vibrational spectroscopy. J Am Chem Soc 2010;132:6914-6916.

[47] Serrano PN, Wang H, Crack JC, al e. Nitrosylation of nitric oxide-sensing regulatory proteins containing [4Fe-4S] clusters gives rise to multiple iron-nitrosyl complexes. Angew Chem Int Ed 2016; In press.

[48] Thomas MR, Brown D, Franzen S, Boxer SG. FTIR and resonance Raman studies of nitric oxide binding to H93G cavity mutants of myoglobin. Biochemistry 2001;40:15047-15056.

[49] Grabarczyk DB, Ash PA, Vincent KA. Infrared spectroscopy provides insight into the role of dioxygen in the nitrosylation pathway of a [2Fe2S] cluster iron-sulfur protein. J Am Chem Soc 2014;136:11236-11239.

[50] Lin ZS, Lo FC, Li CH, et al. Peptide-bound dinitrosyliron complexes (DNICs) and neutral/reduced-form Roussin's red esters (RREs/rRREs): understanding nitrosylation of [Fe-S] clusters leading to the formation of DNICs and RREs using a de novo design strategy. Inorg Chem 2011;50:10417-10431.

[51] Loehr TM, Sanders-Loehr J. Techniques for obtaining resonance Raman spectra of metalloproteins. Methods Enzymol 1993;226:431-470.

[52] Conover RC, Kowal AT, Fu WG, et al. Spectroscopic characterization of the novel iron-sulfur cluster in Pyrococcus furiosus ferredoxin. J Biol Chem 1990;265:8533-8541.

[53] Brereton PS, Duderstadt RE, Staples CR, Johnson MK, Adams MW. Effect of serinate ligation at each of the iron sites of the [Fe4S4] cluster of Pyrococcus furiosus ferredoxin on the redox, spectroscopic, and biological properties. Biochemistry 1999;38:10594-10605.

[54] Fu W, Drozdzewski PM, Davies MD, Sligar SG, Johnson MK. Resonance Raman and magnetic circular dichroism studies of reduced [2Fe-2S] proteins. J Biol Chem 1992;267:15502-15510.

[55] Han S, Czernuszewicz RS, Kimura T, Adams MWW, Spiro TG. Fe $\mathrm{S}_{2}$ protein resonance Raman-spectra revisited - Structural variations among adrenodoxin, ferredoxin, and red paramagnetic protein. J Am Chem Soc 1989;111:3505-3511.

[56] Meyer J, Fujinaga J, Gaillard J, Lutz M. Mutated forms of the [2Fe-2S] ferredoxin from Clostridium pasteurianum with noncysteinyl ligands to the iron-sulfur cluster. Biochemistry 1994;33:13642-13650.

[57] Cosper MM, Jameson GN, Hernandez HL, Krebs C, Huynh BH, Johnson MK. Characterization of the cofactor composition of Escherichia coli biotin synthase. Biochemistry 2004;43:2007-2021.

[58] Crack JC, Munnoch J, Dodd EL, et al. NsrR from Streptomyces coelicolor is a nitric oxide-sensing [4Fe4S] cluster protein with a specialized regulatory function. J Biol Chem 2015;290:12689-12704.

[59] Cramer SP, Xiao Y, Wang H, Guo Y, Smith MC. Nuclear Resonance Vibrational Spectroscopy (NRVS) of Fe-S model compounds, Fe-S proteins, and nitrogenase. Hyperfine Int 2006;170:47-54.

[60] Scheidt WR, Durbin SM, Sage JT. Nuclear resonance vibrational spectroscopy - NRVS. J Inorg Biochem 2005;99:60-71.

[61] Kamali S, Wang $\mathrm{H}$, Mitra D, et al. Observation of the Fe-CN and Fe-CO vibrations in the active site of [NiFe] hydrogenase by nuclear resonance vibrational spectroscopy. Angew Chem Int Ed 2013;52:724 728.

[62] Mitra D, Pelmenschikov V, Guo Y, et al. Dynamics of the [4Fe-4S] Cluster in Pyrococcus furiosus D14C ferredoxin via nuclear resonance vibrational and resonance Raman spectroscopies, force field simulations, and density functional theory calculations. Biochemistry 2011;50:5220-5235.

[63] Smith MC, Xiao Y, Wang $\mathrm{H}$, et al. Normal Mode Analysis of $\left[\mathrm{FeCl}_{4}\right]^{-}$and $\left[\mathrm{Fe}_{2} \mathrm{~S}_{2} \mathrm{Cl}_{4}\right]^{2-}$ via vibrational Mössbauer, resonance Raman, and FT-IR spectroscopy. Inorg Chem 2005;44:5562-5570.

[64] Wang H, Alp E, Yoda Y, Cramer S. A practical guide for nuclear resonance vibrational spectroscopy (NRVS) of biochemical samples and model compounds. In: Fontecilla-Camps JC, Nicolet Y, Eds. Metalloproteins: Humana Press, 2014: 125-137.

[65] Cruz-Ramos H, Crack J, Wu G, et al. NO sensing by FNR: regulation of the Escherichia coli NOdetoxifying flavohaemoglobin, Hmp. EMBO J 2002;21:3235-3244.

[66] Jaworska M, Stasicka Z. Structure and UV-vis spectroscopy of Roussin black salt $\left[\mathrm{Fe}_{4} \mathrm{~S}_{3}(\mathrm{NO})_{7}\right]^{-}$. J Mol Struct 2006;785:68-75. 
[67] Crack JC, Stapleton MR, Green J, Thomson AJ, Le Brun NE. Mechanism of [4Fe-4S](Cys)4 cluster nitrosylation is conserved among NO-responsive regulators. J Biol Chem 2013;288:11492-11502.

[68] Crack JC, Svistunenko DA, Munnoch J, Thomson AJ, Hutchings MI, Le Brun NE. Differentiated, promoterspecific response of [4Fe-4S] NsrR DNA binding to reaction with nitric oxide. J Biol Chem 2016;291:86638672.

[69] Banerjee S, Mazumdar S. Electrospray ionization mass spectrometry: a technique to access the information beyond the molecular weight of the analyte. Int J Anal Chem 2012;2012:282574.

[70] Hopper JT, Robinson CV. Mass spectrometry quantifies protein interactions--from molecular chaperones to membrane porins. Angew Chem Int Ed 2014;53:14002-14015.

[71] Kaltashov IA, Zhang M, Eyles SJ, Abzalimov RR. Investigation of structure, dynamics and function of metalloproteins with electrospray ionization mass spectrometry. Anal Bioanal Chem 2006;386:472-481.

[72] Morgner N, Robinson CV. Linking structural change with functional regulation-insights from mass spectrometry. Curr Opin Struct Biol 2012;22:44-51.

[73] Johnson KA, Verhagen MFJM, Brereton PS, Adams MWW, Amster IJ. Probing the stoichiometry and oxidation states of metal centers in iron-sulfur proteins using electrospray FTICR mass spectrometry. Anal Chem 2000;72:1410-1418.

[74] Munnoch JT, Martinez MT, Svistunenko DA, Crack JC, Le Brun NE, Hutchings MI. Characterization of a putative NsrR homologue in Streptomyces venezuelae reveals a new member of the Rrf2 superfamily. Sci Rep 2016;6:31597.

[75] Enemark JH, Feltham RD. Principles of structure, bonding, and reactivity for metal nitrosyl complexes. Coord Chem Rev 1974;13:339-406.

[76] Ye S, Neese F. The unusual electronic structure of dinitrosyl iron complexes. J Am Chem Soc 2010;132:3646-3647.

[77] Roussin ML. Recherches sur les nitrosulfures doubles de fer. Ann Chim Phys 1858;52:285.

[78] Butler AR, Megson IL. Non-Heme Iron Nitrosyls in Biology. Chem Rev 2002;102:1155-1166.

[79] Johansson G, Lipscomb WN. The structure of Roussin's black salt $\mathrm{CsFe}_{4} \mathrm{~S}_{3}(\mathrm{NO})_{7} \cdot \mathrm{H}_{2} \mathrm{O}$. Acta Crystallog 1958;11:594-598.

[80] D'Addario S, Demartin F, Grossi L, et al. Redox behavior of the black roussinate heptanitrosyltrisulfotetraferrate(1-) monoanion. Synthesis and spectroscopic characterization of the $\left[\mathrm{Fe}_{4} \mathrm{~S}_{3}(\mathrm{NO})_{7}\right]^{\mathrm{n}-}(\mathrm{n}=2,3)$ anions and crystal structures of the mono- and dianions in their $\left[\mathrm{NEt}_{4}\right]^{+}$salts. Inorg Chem 1993;32:1153-1160.

[81] Bourassa J, DeGraff W, Kudo S, Wink DA, Mitchell JB, Ford PC. Photochemistry of Roussin's red salt, $\mathrm{Na}_{2}\left[\mathrm{Fe}_{2} \mathrm{~S}_{2}(\mathrm{NO})_{4}\right]$, and of Roussin's black salt, $\mathrm{NH}_{4}\left[\mathrm{Fe}_{4} \mathrm{~S}_{3}(\mathrm{NO})_{7}\right]$. In situ nitric oxide generation to sensitize Y-radiation induced cell death. J Am Chem Soc 1997;119:2853-2860.

[82] Thomas JT, Robertson JH, Cox EG. The crystal structure of Roussin's red ethyl ester. Acta Crystallog 1958;11:599-604.

[83] Lu T-T, Tsou C-C, Huang H-W, et al. Anionic Roussin's red esters (RREs) syn-/anti-[Fe $\left.(\mu-\mathrm{SEt})(\mathrm{NO})_{2}\right]^{2-}$ : the critical role of thiolate ligands in regulating the transformation of RREs into dinitrosyl iron complexes and the anionic RREs. Inorg Chem 2008;47:6040-6050.

[84] Tonzetich ZJ, Do LH, Lippard SJ. Dinitrosyl iron complexes relevant to Rieske cluster nitrosylation. J Am Chem Soc 2009;131:7964-7965.

[85] Bryar TR, Eaton DR. Electronic configuration and structure of paramagnetic iron dinitrosyl complexes. Can J Chem 1992;70:1917-1926.

[86] Ting-Wah Chu C, Yip-Kwai Lo F, Dahl LF. Synthesis and stereochemical analysis of the $\left[\mathrm{Fe}_{4}(\mathrm{NO})_{4}\left(\mu_{3}-\right.\right.$ $\left.S)_{4}\right]^{n}$ series $(n=0,-1)$ which possesses a cubane like $\mathrm{Fe}_{4} \mathrm{~S}_{4}$ core: direct evidence for the antibonding tetrametal character of the unpaired electron upon a one-electron reduction of a completely bonding tetrahedral metal cluster. J Am Chem Soc 1982;104:3409-3422.

[87] Tsou C-C, Lin Z-S, Lu T-T, Liaw W-F. Transformation of dinitrosyl iron complexes $\left[(\mathrm{NO})_{2} \mathrm{Fe}(\mathrm{SR})_{2}\right]^{-}(\mathrm{R}=$ $\mathrm{Et}, \mathrm{Ph})$ into $[4 \mathrm{Fe}-4 \mathrm{~S}]$ Clusters $\left[\mathrm{Fe}_{4} \mathrm{~S}_{4}(\mathrm{SPh})_{4}\right]^{2-}$ : Relevance to the repair of the nitric oxide-modified ferredoxin [4Fe-4S] clusters. J Am Chem Soc 2008;130:17154-17160.

[88] Victor E, Lippard SJ. A Tetranitrosyl [4Fe-4S] cluster forms en route to Roussin's black anion: Nitric oxide reactivity of $\left[\mathrm{Fe}_{4} \mathrm{~S}_{4}\left(\mathrm{LS}_{3}\right) \mathrm{L}^{\prime}\right]_{2}$. Inorg Chem 2014;53:5311-5320.

[89] Conrado CL, Bourassa JL, Egler C, Wecksler S, Ford PC. Photochemical Investigation of Roussin's red salt esters: $\mathrm{Fe}_{2}(\mu-\mathrm{SR})_{2}(\mathrm{NO})_{4}$. Inorg Chem 2003;42:2288-2293.

[90] Seyferth D, Gallagher MK, Cowie M. The bridging sulfide anion reactivity of Roussin's red salt. Organometallics 1986;5:539-548.

[91] Sung SS, Glidewell C, Butler AR, Hoffmann R. Bonding in nitrosylated iron-sulfur clusters. Inorg Chem 1985;24:3856-3859.

[92] Glidewell C, Lambert RJ, Harman ME, Hursthouse MB. Reactions of nucleophiles with bis( $\mu$-thiosulphato$S)$-bis(dinitrosylferrate)(2-), $\left[\mathrm{Fe}_{2}\left(\mathrm{~S}_{2} \mathrm{O}_{3}\right)_{2}(\mathrm{NO})_{4}\right]^{2-}$, and of electrophiles with heptanitrosyltri- $\mu_{3}$-thiotetraferrate(1-), $\left[\mathrm{Fe}_{4} \mathrm{~S}_{3}(\mathrm{NO})_{7}\right]$ : new routes to bis( $\mu$-organothiolato)-bis(dinitrosyliron) complexes $\left[\mathrm{Fe}_{2}(\mathrm{SR})_{2}(\mathrm{NO})_{4}\right]$ and the crystal and molecular structure of trimethylsulphonium heptanitrosyltri- $\mu_{3}$-thiotetraferrate(1-), $\mathrm{SMe}_{3}\left[\mathrm{Fe}_{4} \mathrm{~S}_{3}(\mathrm{NO})_{7}\right]$. Dalton Trans 1990:2685-2690.

[93] Butler AR, Glidewell C, Glidewell SM. Formation of the heptanitrosyltri- $\mu_{3}$-thioxotetraferrate $(1-)$ anion, $\left[\mathrm{Fe}_{4} \mathrm{~S}_{3}(\mathrm{NO})_{7}\right]^{-}$by capture of biological sulphur in reaction. Polyhedron 1990;9:2399-2405. 
[94] Butler AR, Glidewell C, Hyde AR, Walton JC. Formation of paramagnetic mononuclear iron nitrosyl complexes from diamagnetic di- and tetranuclear iron-sulphur nitrosyls: characterisation by EPR spectroscopy and study of thiolate and nitrosyl ligand exchange reactions. Polyhedron 1985;4:797-809.

[95] Harrop TC, Tonzetich ZJ, Reisner E, Lippard SJ. Reactions of synthetic [2Fe-2S] and [4Fe-4S] clusters with nitric oxide and nitrosothiols. J Am Chem Soc 2008;130:15602-15610.

[96] Harrop TC, Song D, Lippard SJ. Reactivity pathways for nitric oxide and nitrosonium with iron complexes in biologically relevant sulfur coordination spheres. J Inorg Biochem 2007;101:1730-1738.

[97] Lu T-T, Chiou S-J, Chen C-Y, Liaw W-F. Mononitrosyl tris(thiolate) iron complex $\left[\mathrm{Fe}(\mathrm{NO})(\mathrm{SPh})_{3}\right]^{-}$and dinitrosyl iron complex $\left[(\mathrm{EtS})_{2} \mathrm{Fe}(\mathrm{NO})_{2}\right]$ : : Formation pathway of dinitrosyl iron complexes (DNICs) from nitrosylation of biomimetic rubredoxin $\left[\mathrm{Fe}(\mathrm{SR})_{4}\right]^{2-1 /}-(\mathrm{R}=\mathrm{Ph}, \mathrm{Et})$. Inorg Chem 2006;45:8799-8806.

[98] Zheng P, Li H. Highly covalent ferric-thiolate bonds exhibit surprisingly low mechanical stability. J Am Chem Soc 2011;133:6791-6798.

[99] Fitzpatrick J, Kim E. New Synthetic routes to iron-sulfur clusters: Deciphering the repair chemistry of [2Fe-2S] clusters from mononitrosyl iron complexes. Inorg Chem 2015;54:10559-10567.

[100] Fitzpatrick J, Kim E. Synthetic modeling chemistry of iron-sulfur clusters in nitric oxide signaling. Acc Chem Res 2015;48:2453-2461.

[101] Rogers PA, Eide L, Klungland A, Ding H. Reversible inactivation of E. coli endonuclease III via modification of its [4Fe-4S] cluster by nitric oxide. DNA Repair 2003;2:809-817.

[102] Bouton C, Chauveau M-J, Lazereg S, Drapier J-C. Recycling of RNA binding iron regulatory protein 1 into an aconitase after nitric oxide removal depends on mitochondrial ATP. J Biol Chem 2002;277:3122031227.

[103] Lu T-T, Huang H-W, Liaw W-F. Anionic mixed thiolate-sulfide-bridged Roussin's red esters $\left[(\mathrm{NO}){ }_{2} \mathrm{Fe}(\mu-\right.$ $\left.\mathrm{SR})(\mu-\mathrm{S}) \mathrm{Fe}(\mathrm{NO})_{2}\right]^{-}(\mathrm{R}=\mathrm{Et}, \mathrm{Me}, \mathrm{Ph})$ : A key intermediate for transformation of dinitrosyl iron complexes (DNICs) to [2Fe-2S] clusters. Inorg Chem 2009;48:9027-9035.

[104] Fitzpatrick J, Kalyvas H, Shearer J, Kim E. Dioxygen mediated conversion of $\left\{\mathrm{Fe}(\mathrm{NO})_{2}\right\}^{9}$ dinitrosyl iron complexes to Roussin's red esters. Cheml Commun 2013;49:5550-5552.

[105] Tan LL, Holm RH, Lee SC. Structural analysis of cubane-type iron clusters. Polyhedron 2013;58:206-217.

[106] Spiro S. Regulators of bacterial responses to nitric oxide. FEMS Microbiol Rev 2007;31:193-211.

[107] Kommineni S, Lama A, Popescu B, Nakano MM. Global transcriptional control by NsrR in Bacillus subtilis. J Bacteriol 2012;194:1679-1688.

[108] Vine CE, Purewal SK, Cole JA. NsrR-dependent method for detecting nitric oxide accumulation in the Escherichia coli cytoplasm and enzymes involved in NO production. FEMS Microbiol Lett 2011;325:108114.

[109] Filenko N, Spiro S, Browning DF, et al. The NsrR regulon of Escherichia coli K-12 includes genes encoding the hybrid cluster protein and the periplasmic, respiratory nitrite reductase. J Bacteriol 2007;189:44104417.

[110] Hutchings MI, Mandhana N, Spiro S. The NorR protein of Escherichia coli activates expression of the flavorubredoxin gene norV in response to reactive nitrogen species. J Bacteriol 2002;184:4640-4643.

[111] D'Autreaux B, Tucker NP, Dixon R, Spiro S. A non-haem iron centre in the transcription factor NorR senses nitric oxide. Nature 2005;437:769-772.

[112] Bush M, Ghosh T, Tucker N, Zhang X, Dixon R. Transcriptional regulation by the dedicated nitric oxide sensor, NorR: a route towards NO detoxification. Biochem Soc Trans 2011;39:289-293.

[113] Weissbach H, Brot N. Regulation of methionine synthesis in Escherichia coli. Mol Microbiol 1991;5:15931597.

[114] Pullan ST, Gidley MD, Jones RA, et al. Nitric oxide in chemostat-cultured Escherichia coli is sensed by Fnr and other global regulators: unaltered methionine biosynthesis indicates lack of $S$ nitrosation. $J$ Bacteriol 2007;189:1845-1855.

[115] Karp PD, Weaver D, Paley S, et al. The EcoCyc Database. EcoSal Plus 2014;6.

[116] Pomposiello PJ, Demple B. Redox-operated genetic switches: the SoxR and OxyR transcription factors. Trends Biotechnol 2001;19:109-114.

[117] Tang Y, Quail MA, Artymiuk PJ, Guest JR, Green J. Escherichia coli aconitases and oxidative stress: posttranscriptional regulation of SodA expression. Microbiol 2002;148:1027-1037.

[118] Flatley J, Barrett J, Pullan ST, Hughes MN, Green J, Poole RK. Transcriptional responses of Escherichia coli to S-nitrosoglutathione under defined chemostat conditions reveal major changes in methionine biosynthesis. J Biol Chem 2005;280:10065-10072.

[119] Laver JR, Stevanin TM, Messenger SL, et al. Bacterial nitric oxide detoxification prevents host cell Snitrosothiol formation: a novel mechanism of bacterial pathogenesis. FASEB J 2010;24:286-295.

[120] Kommineni S, Yukl E, Hayashi T, et al. Nitric oxide-sensitive and -insensitive interaction of Bacillus subtilis NsrR with a ResDE-controlled promoter. Mol Microbiol 2010;78:1280-1293.

[121] Keon RG, Fu R, Voordouw G. Deletion of two downstream genes alters expression of the $h m c$ operon of Desulfovibrio vulgaris subsp. vulgaris Hildenborough. Arch Microbiol 1997;167:376-383.

[122] Shepard W, Soutourina O, Courtois E, England P, Haouz A, Martin-Verstraete I. Insights into the Rrf2 repressor family--the structure of CymR, the global cysteine regulator of Bacillus subtilis. FEBS J 2011;278:2689-2701.

[123] Nakano MM, Kominos-Marvell W, Sane B, et al. spxA2, encoding a regulator of stress resistance in Bacillus anthracis, is controlled by SaiR, a new member of the Rrf2 protein family. Mol Microbiol 2014;94:815-827. 
[124] Todd JD, Sawers G, Johnston AW. Proteomic analysis reveals the wide-ranging effects of the novel, ironresponsive regulator RirA in Rhizobium leguminosarum bv. viciae. Mol Genet Genom 2005;273:197-206.

[125] Rajagopalan S, Teter SJ, Zwart PH, Brennan RG, Phillips KJ, Kiley PJ. Studies of IscR reveal a unique mechanism for metal-dependent regulation of DNA binding specificity. Nat Struct Mol Biol 2013;20:740747.

[126] Yukl ET, Elbaz MA, Nakano MM, Moenne-Loccoz P. Transcription factor NsrR from Bacillus subtilis senses nitric oxide with a 4Fe-4S Cluster. Biochemistry 2008;47:13084-13092.

[127] Tanous C, Soutourina O, Raynal B, et al. The CymR regulator in complex with the enzyme CysK controls cysteine metabolism in Bacillus subtilis. J Biol Chem 2008;283:35551-35560.

[128] Tucker NP, Hicks MG, Clarke TA, et al. The transcriptional repressor protein NsrR senses nitric oxide directly via a [2Fe-2S] cluster. PLoS ONE 2008;3:e3623.

[129] Calzolai L GC, Zhao ZH, Teng Q, Adams MW, La Mar GN. 1H NMR investigation of the electronic and molecular structure of the four-iron cluster ferredoxin from the hyperthermophile Pyrococcus furiosus. Identification of Asp 14 as a cluster ligand in each of the four redox states. Biochemistry 1995;34:1137311384.

[130] George SJ, Armstrong FA, Hatchikian EC, Thomson AJ. Electrochemical and spectroscopic characterization of the conversion of the 7Fe into the 8Fe form of ferredoxin III from Desulfovibrio africanus. Identification of a [4Fe-4S] cluster with one non-cysteine ligand. Biochem J 1989;264:275-284.

[131] Gruner I, Fradrich C, Bottger LH, Trautwein AX, Jahn D, Hartig E. Aspartate 141 is the fourth ligand of the oxygen-sensing [4Fe-4S] ${ }^{2+}$ cluster of Bacillus subtilis transcriptional regulator Fnr. J Biol Chem $2011 ; 286: 2017-2021$.

[132] Crack JC, Hutchings MI, Thomson AJ, Le Brun NE. Biochemical properties of Paracoccus denitrificans FnrP: reactions with molecular oxygen and nitric oxide. J Biol Inorg Chem 2016;21:71-82.

[133] Volbeda A, Darnault C, Renoux O, Nicolet Y, Fontecilla-Camps JC. The crystal structure of the global anaerobic transcriptional regulator FNR explains its extremely fine-tuned monomer-dimer equilibrium. Sci Adv 2015;1:e1501086.

[134] Popescu CV, Bates DM, Beinert H, Munck E, Kiley PJ. Mössbauer spectroscopy as a tool for the study of activation/inactivation of the transcription regulator FNR in whole cells of Escherichia coli. Proc Natl Acad Sci USA 1998;95:13431-13435.

[135] Moore LJ, Mettert EL, Kiley PJ. Regulation of FNR Dimerization by Subunit Charge Repulsion. J Biol Chem 2006;281:33268-33275.

[136] Moore LJ, Kiley PJ. Characterization of the dimerization domain in the FNR transcription factor. J Biol Chem 2001;276:45744-45750.

[137] Khoroshilova N, Popescu C, Munck E, Beinert H, Kiley PJ. Iron-sulfur cluster disassembly in the FNR protein of Escherichia coli by $\mathrm{O}_{2}$ : [4Fe-4S] to [2Fe-2S] conversion with loss of biological activity. Proc Natl Acad Sci USA 1997;94:6087-6092.

[138] Lazazzera BA, Beinert H, Khoroshilova N, Kennedy MC, Kiley PJ. DNA binding and dimerization of the Fe-S-containing FNR protein from Escherichia coli are regulated by oxygen. J Biol Chem 1996;271:27622768.

[139] Crack JC, Gaskell AA, Green J, Cheesmant MR, Le Brun NE, Thomson AJ. Influence of the environment on the $[4 \mathrm{Fe}-4 \mathrm{~S}]^{2+}$ to $[2 \mathrm{Fe}-2 \mathrm{~S}]^{2+}$ cluster switch in the transcriptional regulator FNR. J Am Chem Soc 2008;130:1749-1758.

[140] Zhang B, Crack JC, Subramanian S, et al. Reversible cycling between cysteine persulfide-ligated [2Fe2S] and cysteine-ligated [4Fe-4S] clusters in the FNR regulatory protein. Proc Natl Acad Sci USA 2012;109:15734-15739.

[141] Crack JC, Stapleton MR, Green J, Thomson AJ, Le Brun NE. Influence of association state and DNA binding on the $\mathrm{O}_{2}$-reactivity of $[4 \mathrm{Fe}-4 \mathrm{~S}]$ fumarate and nitrate reduction (FNR) regulator. Biochem $\mathrm{J}$ 2014;463:83-92.

[142] Jervis AJ, Crack JC, White G, et al. The $\mathrm{O}_{2}$ sensitivity of the transcription factor FNR is controlled by Ser24 modulating the kinetics of [4Fe-4S] to [2Fe-2S] conversion. Proc Natl Acad Sci USA 2009;106:4659-4664.

[143] Yan A, Kiley PJ. Dissecting the role of the N-terminal region of the Escherichia coli global transcription factor FNR. J Bacteriol 2008;190:8230-8233.

[144] Sutton VR, Stubna A, Patschkowski T, Munck E, Beinert H, Kiley PJ. Superoxide destroys the [2Fe-2S ${ }^{2+}$ cluster of FNR from Escherichia coli. Biochemistry 2004;43:791-798.

[145] Bates DM, Popescu CV, Khoroshilova N, et al. Substitution of leucine 28 with histidine in the Escherichia coli transcription factor FNR results in increased stability of the $[4 \mathrm{Fe}-4 \mathrm{~S}]^{2+}$ cluster to oxygen. J Biol Chem 2000;275:6234-6240.

[146] Kiley PJ, Beinert H. Oxygen sensing by the global regulator, FNR: the role of the iron-sulfur cluster. FEMS Microbiol Rev 1999;22:341-352.

[147] Kim SO, Orii Y, Lloyd D, Hughes MN, Poole RK. Anoxic function for the Escherichia coli flavohaemoglobin (Hmp): reversible binding of nitric oxide and reduction to nitrous oxide. FEBS Lett 1999;445:389-394.

[148] Wang J, Vine CE, Balasiny BK, et al. The roles of the hybrid cluster protein, Hcp and its reductase, Hcr, in high affinity nitric oxide reduction that protects anaerobic cultures of Escherichia coli against nitrosative stress. Mol Microbiol 2016;100:877-892.

[149] Hutchings MI, Crack JC, Shearer N, Thompson BJ, Thomson AJ, Spiro S. Transcription factor FnrP from Paracoccus denitrificans contains an iron-sulfur cluster and is activated by anoxia: identification of essential cysteine residues. J Bacteriol 2002;184:503-508. 
[150] Otten MF, Stork DM, Reijnders WN, Westerhoff HV, Van Spanning RJ. Regulation of expression of terminal oxidases in Paracoccus denitrificans. Eur J Biochem 2001;268:2486-2497.

[151] Bergaust L, van Spanning RJ, Frostegard A, Bakken LR. Expression of nitrous oxide reductase in Paracoccus denitrificans is regulated by oxygen and nitric oxide through FnrP and NNR. Microbiology 2012;158:826-834.

[152] Lee YY, Shearer N, Spiro S. Transcription factor NNR from Paracoccus denitrificans is a sensor of both nitric oxide and oxygen: isolation of $n n r^{\star}$ alleles encoding effector-independent proteins and evidence for a haem-based sensing mechanism. Microbiology 2006;152:1461-1470.

[153] Altschul SF, Gish W, Miller W, Myers EW, Lipman DJ. Basic local alignment search tool. J Mol Biol 1990;215:403-410.

[154] Averina OV, Zakharevich NV, Danilenko VN. Identification and characterization of WhiB-like family proteins of the Bifidobacterium genus. Anaerobe 2012;18:421-429.

[155] Geiman DE, Raghunand TR, Agarwal N, Bishai WR. Differential gene expression in response to exposure to antimycobacterial agents and other stress conditions among seven Mycobacterium tuberculosis whiBlike genes. Antimicrob Agents Chemother 2006;50:2836-2841.

[156] den Hengst CD, Buttner MJ. Redox control in actinobacteria. Biochim Biophys Acta 2008;1780:12011216.

[157] Lee JY, Park JS, Kim HJ, Kim Y, Lee HS. Corynebacterium glutamicum whcB, a stationary phase-specific regulatory gene. FEMS Microbiol Lett 2012;327:103-109.

[158] Alam MS, Garg SK, Agrawal P. Studies on structural and functional divergence among seven WhiB proteins of Mycobacterium tuberculosis H37Rv. FEBS J 2009;276:76-93.

[159] Garg SK, Suhail Alam M, Soni V, Radha Kishan KV, Agrawal P. Characterization of Mycobacterium tuberculosis WhiB1/Rv3219 as a protein disulfide reductase. Protein Expr Purif 2007;52:422-432.

[160] Alam MS, Garg SK, Agrawal P. Molecular function of WhiB4/Rv3681c of Mycobacterium tuberculosis H37Rv: a [4Fe-4S] cluster co-ordinating protein disulphide reductase. Mol Microbiol 2007;63:1414-1431.

[161] Crack JC, den Hengst CD, Jakimowicz P, et al. Characterization of [4Fe-4S]-containing and cluster-free forms of Streptomyces WhiD. Biochemistry 2009;48:12252-12264.

[162] Garg S, Alam MS, Bajpai R, Kishan KR, Agrawal P. Redox biology of Mycobacterium tuberculosis H37Rv: protein-protein interaction between GlgB and WhiB1 involves exchange of thiol-disulfide. BMC Biochem 2009;10:1.

[163] Konar M, Alam MS, Arora C, Agrawal P. WhiB2/Rv3260c, a cell division-associated protein of Mycobacterium tuberculosis H37Rv, has properties of a chaperone. FEBS J 2012;279:2781-2792.

[164] Rybniker J, Nowag A, van Gumpel E, et al. Insights into the function of the WhiB-like protein of mycobacteriophage TM4--a transcriptional inhibitor of WhiB2. Mol Microbiol 2010;77:642-657.

[165] Casonato S, Cervantes Sanchez A, Haruki H, et al. WhiB5, a transcriptional regulator that contributes to Mycobacterium tuberculosis virulence and reactivation. Infection and immunity 2012;80:3132-3144.

[166] Facey PD, Sevcikova B, Novakova R, et al. The dpsA gene of Streptomyces coelicolor. induction of expression from a single promoter in response to environmental stress or during development. PLoS One 2011;6:e25593.

[167] Bush MJ, Chandra G, Bibb MJ, Findlay KC, Buttner MJ. Genome-wide chromatin immunoprecipitation sequencing analysis shows that WhiB is a transcription factor that co-controls its regulon with WhiA to initiate developmental cell division in Streptomyces. MBio 2016;7:e00523-00516.

[168] Agarwal N, Raghunand TR, Bishai WR. Regulation of the expression of whiB1 in Mycobacterium tuberculosis: role of cAMP receptor protein. Microbiology 2006;152:2749-2756.

[169] Stapleton MR, Smith LJ, Hunt DM, Buxton RS, Green J. Mycobacterium tuberculosis WhiB1 represses transcription of the essential chaperonin GroEL2. Tuberculosis 2012;92:328-332.

[170] Raghunand TR, Bishai WR. Mapping essential domains of Mycobacterium smegmatis WhmD: insights into WhiB structure and function. J Bacteriol 2006;188:6966-6976.

[171] Raghunand TR, Bishai WR. Mycobacterium smegmatis whmD and its homologue Mycobacterium tuberculosis whiB2 are functionally equivalent. Microbiology 2006;152:2735-2747.

[172] Singh A, Crossman DK, Mai D, et al. Mycobacterium tuberculosis WhiB3 maintains redox homeostasis by regulating virulence lipid anabolism to modulate macrophage response. PLoS Pathog 2009;5:e1000545.

[173] Saini V, Farhana A, Steyn AJ. Mycobacterium tuberculosis WhiB3: a novel iron-sulfur cluster protein that regulates redox homeostasis and virulence. Antioxid Redox Signal 2012;16:687-697.

[174] Singh A, Guidry L, Narasimhulu KV, et al. Mycobacterium tuberculosis WhiB3 responds to $\mathrm{O}_{2}$ and nitric oxide via its [4Fe-4S] cluster and is essential for nutrient starvation survival. Proc Natl Acad Sci USA 2007;104:11562-11567.

[175] Saini V, Cumming BM, Guidry L, et al. Ergothioneine maintains redox and bioenergetic homeostasis essential for drug susceptibility and virulence of Mycobacterium tuberculosis. Cell Rep 2016;14:572-585.

[176] Richard-Greenblatt M, Bach H, Adamson J, et al. Regulation of ergothioneine biosynthesis and its effect on Mycobacterium tuberculosis growth and infectivity. J Biol Chem 2015;290:23064-23076.

[177] Mehta M, Rajmani RS, Singh A. Mycobacterium tuberculosis WhiB3 responds to vacuolar pH-induced changes in mycothiol redox potential to modulate phagosomal maturation and virulence. J Biol Chem 2016;291:2888-2903.

[178] Chawla M, Parikh P, Saxena A, et al. Mycobacterium tuberculosis WhiB4 regulates oxidative stress response to modulate survival and dissemination in vivo. Mol Microbiol 2012;85:1148-1165. 
[179] Guimaraes BG, Souchon H, Honore N, et al. Structure and mechanism of the alkyl hydroperoxidase AhpC, a key element of the Mycobacterium tuberculosis defense system against oxidative stress. J Biol Chem 2005;280:25735-25742.

[180] Larsson C, Luna B, Ammerman NC, Maiga M, Agarwal N, Bishai WR. Gene expression of Mycobacterium tuberculosis putative transcription factors whiB1-7 in redox environments. PLoS One 2012;7:e37516.

[181] Ramon-Garcia S, Ng C, Jensen PR, et al. WhiB7, an Fe-S-dependent transcription factor that activates species-specific repertoires of drug resistance determinants in actinobacteria. $J$ Biol Chem 2013;288:34514-34528.

[182] Burian J, Yim G, Hsing M, et al. The mycobacterial antibiotic resistance determinant WhiB7 acts as a transcriptional activator by binding the primary sigma factor SigA (RpoV). Nucleic Acids Res 2013;41:10062-10076.

[183] Burian J, Ramon-Garcia S, Sweet G, Gomez-Velasco A, Av-Gay Y, Thompson CJ. The mycobacterial transcriptional regulator whiB7 gene links redox homeostasis and intrinsic antibiotic resistance. J Biol Chem 2012;287:299-310.

[184] Fowler-Goldsworthy K, Gust B, Mouz S, Chandra G, Findlay KC, Chater KF. The actinobacteria-specific gene wblA controls major developmental transitions in Streptomyces coelicolor A3(2). Microbiology $2011 ; 157: 1312-1328$.

[185] Jakimowicz P, Cheesman MR, Bishai WR, Chater KF, Thomson AJ, Buttner MJ. Evidence that the Streptomyces developmental protein WhiD, a member of the WhiB family, binds a [4Fe-4S] cluster. J Biol Chem 2005;280:8309-8315.

[186] Molle V, Palframan WJ, Findlay KC, Buttner MJ. WhiD and WhiB, homologous proteins required for different stages of sporulation in Streptomyces coelicolor A3(2). J Bacteriology 2000;182:1286-1295.

[187] Yoo JS, Oh GS, Ryoo S, Roe JH. Induction of a stable sigma factor SigR by translation-inhibiting antibiotics confers resistance to antibiotics. Sci Rep 2016;6:28628.

[188] Bus JS, Gibson JE. Paraquat: model for oxidant-initiated toxicity. Environ Health Perspect 1984;55:37-46.

[189] Bradley TM, Hidalgo E, Leautaud V, Ding H, Demple B. Cysteine-to-alanine replacements in the Escherichia coli SoxR protein and the role of the [2Fe-2S] centers in transcriptional activation. Nucleic Acids Res 1997;25:1469-1475.

[190] Singh AK, Shin JH, Lee KL, Imlay JA, Roe JH. Comparative study of SoxR activation by redox-active compounds. Molecular Microbiol 2013;90:983-996.

[191] Watanabe S, Kita A, Kobayashi K, Miki K. Crystal structure of the [2Fe-2S] oxidative-stress sensor SoxR bound to DNA. Proc Natl Acad Sci USA 2008;105:4121-4126.

[192] Koo MS, Lee JH, Rah SY, et al. A reducing system of the superoxide sensor SoxR in Escherichia coli. EMBO J 2003;22:2614-2622.

[193] Gorodetsky AA, Dietrich LE, Lee PE, Demple B, Newman DK, Barton JK. DNA binding shifts the redox potential of the transcription factor SoxR. Proc Natl Acad Sci USA 2008;105:3684-3689.

[194] Kobayashi K, Fujikawa M, Kozawa T. Binding of promoter DNA to SoxR protein decreases the reduction potential of the [2Fe-2S] cluster. Biochemistry 2015;54:334-339.

[195] Gu M, Imlay JA. The SoxRS response of Escherichia coli is directly activated by redox-cycling drugs rather than by superoxide. Molecular Microbiol 2011;79:1136-1150.

[196] Siedler S, Schendzielorz G, Binder S, Eggeling L, Bringer S, Bott M. SoxR as a single-cell biosensor for NADPH-consuming enzymes in Escherichia coli. ACS Synth Biol 2014;3:41-47.

[197] Krapp AR, Humbert MV, Carrillo N. The soxRS response of Escherichia colican be induced in the absence of oxidative stress and oxygen by modulation of NADPH content. Microbiology 2011;157:957-965.

[198] Gaudu P, Dubrac S, Touati D. Activation of SoxR by overproduction of desulfoferrodoxin: multiple ways to induce the soxRS regulon. J Bacteriology 2000;182:1761-1763.

[199] Shin JH, Singh AK, Cheon DJ, Roe JH. Activation of the SoxR regulon in Streptomyces coelicolor by the extracellular form of the pigmented antibiotic actinorhodin. J Bacteriology 2011;193:75-81.

[200] Lee KL, Singh AK, Heo L, Seok C, Roe JH. Factors affecting redox potential and differential sensitivity of SoxR to redox-active compounds. Mol Microbiol 2015;97:808-821.

[201] Nunoshiba T, deRojas-Walker T, Wishnok JS, Tannenbaum SR, Demple B. Activation by nitric oxide of an oxidative-stress response that defends Escherichia coli against activated macrophages. Proc Natl Acad Sci USA 1993;90:9993-9997.

[202] Ding H, Demple B. Direct nitric oxide signal transduction via nitrosylation of iron-sulfur centers in the SoxR transcription activator. Proc Natl Acad Sci USA 2000;97:5146-5150.

[203] Fujikawa M, Kobayashi K, Kozawa T. Mechanistic studies on formation of the dinitrosyl iron complex of the [2Fe-2S] cluster of SoxR protein. J Biochem 2014;156:163-172.

[204] Lo FC, Lee JF, Liaw WF, et al. The metal core structures in the recombinant Escherichia colitranscriptional factor SoxR. Chemistry 2012;18:2565-2577.

[205] Lo FC, Chen CL, Lee CM, et al. A study of NO trafficking from dinitrosyl-iron complexes to the recombinant E. coli transcriptional factor SoxR. J Biol Inorg Chem 2008;13:961-972.

[206] Nunoshiba T, DeRojas-Walker T, Tannenbaum SR, Demple B. Roles of nitric oxide in inducible resistance of Escherichia coli to activated murine macrophages. Infection and immunity 1995;63:794-798.

[207] Fang FC, Vazquez-Torres A, Xu Y. The transcriptional regulator SoxS is required for resistance of Salmonella typhimurium to paraquat but not for virulence in mice. Infection and immunity 1997;65:53715375. 
[208] Eriksson S, Lucchini S, Thompson A, Rhen M, Hinton JC. Unravelling the biology of macrophage infection by gene expression profiling of intracellular Salmonella enterica. Mol Microbiol 2003;47:103-118.

[209] Recalcati S, Minotti G, Cairo G. Iron regulatory proteins: from molecular mechanisms to drug development. Antioxid Redox Signal 2010;13:1593-1616.

[210] Volz K. The functional duality of iron regulatory protein 1. Curr Opin Struct Biol 2008;18:106-111.

[211] Zhang DL, Ghosh MC, Rouault TA. The physiological functions of iron regulatory proteins in iron homeostasis - an update. Front Pharmacol 2014;5:124.

[212] Kennedy MC, Antholine WE, Beinert H. An EPR investigation of the products of the reaction of cytosolic and mitochondrial aconitases with nitric oxide. J Biol Chem 1997;272:20340-20347.

[213] Stys A, Galy B, Starzynski RR, et al. Iron regulatory protein 1 outcompetes iron regulatory protein 2 in regulating cellular iron homeostasis in response to nitric oxide. J Biol Chem 2011;286:22846-22854.

[214] Varghese S, Tang Y, Imlay JA. Contrasting sensitivities of Escherichia coli aconitases A and B to oxidation and iron depletion. J Bacteriol 2003;185:221-230.

[215] Jordan PA, Tang Y, Bradbury AJ, Thomson AJ, Guest JR. Biochemical and spectroscopic characterization of Escherichia coli aconitases (AcnA and AcnB). Biochem J 1999;344:739-746.

[216] Tang Y, Guest JR. Direct evidence for mRNA binding and post-transcriptional regulation by Escherichia coli aconitases. Microbiology 1999;145:3069-3079.

[217] Boutrin MC, Wang C, Aruni W, Li X, Fletcher HM. Nitric oxide stress resistance in Porphyromonas gingivalis is mediated by a putative hydroxylamine reductase. J Bacteriol 2012;194:1582-1592.

[218] Figueiredo MC, Lobo SA, Sousa SH, et al. Hybrid cluster proteins and flavodiiron proteins afford protection to Desulfovibrio vulgaris upon macrophage infection. J Bacteriol 2013;195:2684-2690.

[219] Karlinsey JE, Bang IS, Becker LA, et al. The NsrR regulon in nitrosative stress resistance of Salmonella enterica serovar Typhimurium. Mol Microbiol 2012;85:1179-1193.

[220] Lewis JP, Yanamandra SS, Anaya-Bergman C. HcpR of Porphyromonas gingivalis is required for growth under nitrosative stress and survival within host cells. Infect Immun 2012;80:3319-3331.

[221] Aragao D, Mitchell EP, Frazao CF, Carrondo MA, Lindley PF. Structural and functional relationships in the hybrid cluster protein family: structure of the anaerobically purified hybrid cluster protein from Desulfovibrio vulgaris at $1.35 \AA$ resolution. Acta Crystallogr D Biol Crystallogr 2008;64:665-674.

[222] Aragao D, Macedo S, Mitchell EP, et al. Reduced hybrid cluster proteins (HCP) from Desulfovibrio desulfuricans ATCC 27774 and Desulfovibrio vulgaris (Hildenborough): X-ray structures at high resolution using synchrotron radiation. J Biol Inorg Chem 2003;8:540-548.

[223] Cooper SJ, Garner CD, Hagen WR, Lindley PF, Bailey S. Hybrid-cluster protein (HCP) from Desulfovibrio vulgaris (Hildenborough) at $1.6 \AA$ resolution. Biochemistry 2000;39:15044-15054.

[224] Cadby IT, Ibrahim SA, Faulkner M, et al. Regulation, sensory domains and roles of two Desulfovibrio desulfuricans ATCC27774 Crp family transcription factors, HcpR1 and HcpR2, in response to nitrosative stress. Mol Microbiol 2016.

[225] Sievers F, Wilm A, Dineen D, et al. Fast, scalable generation of high-quality protein multiple sequence alignments using Clustal Omega. Mol Syst Biol 2011;7:539.

[226] Kwon HJ, Bennik MH, Demple B, Ellenberger T. Crystal structure of the Escherichia coli Rob transcription factor in complex with DNA. Nat Struct Biol 2000;7:424-430.

[227] van den Berg WA, Hagen WR, van Dongen WM. The hybrid-cluster protein ('prismane protein') from Escherichia coli. Characterization of the hybrid-cluster protein, redox properties of the [2Fe-2S] and [4Fe2S-2O] clusters and identification of an associated NADH oxidoreductase containing FAD and [2Fe-2S]. Eur J Biochem 2000;267:666-676. 


\section{Figure legends}

Fig. 1. Iron-sulfur clusters common in nature. Structures of (a) [2Fe-2S], (b) [4Fe-4S], and (c) [3Fe-4S] iron-sulfur clusters (PDB: 1I7H, 2VKR). Iron, sulfide and cysteine residues are indicated.

Fig. 2. Molecular orbital diagram for nitric oxide.

Fig. 3. Base structures of Roussin's black salt, Roussin's red salt and ester, and mono- and dinitrosyl iron complexes.

Fig. 4. Interconversion of $2 \mathrm{Fe}$ and $4 \mathrm{Fe}$ iron-sulfur cluster nitrosyl species [91].

Fig. 5. Dependence of the final products of Fe-S nitrosylation on redox environment and solvent conditions $[95,96]$

Fig. 6: Interconversion between nitrosylated and parent cluster species. Inorganic [2Fe-2S] and [4Fe-4S] clusters can be re-formed from nitrosylated species synthetically [87, 88, 99, 103].

Fig. 7. Conserved Rrf2 cluster binding motif. Partial Clustal Omega [225] alignment of selected IscR, NsrR, RsrR and RirA proteins. Conserved cysteine residues are highlighted. Bs, B. subtilis; Ec, E. coli; Sc, S. coelicolor. Sv, S. venezuelae; Rz, R. leguminosarum.

Fig. 8. Rrf2 crystal structures. Annotated structures of (a) CymR (PDB:3T8T) and (b) apoIscR (PDB: 4HF1) monomers. In the case of IscR, the three conserved Cys residues that coordinate the cluster were replaced by Ala residues to permit crystallisation. The positions of the substituted cluster ligating residues (space filling) A92, A98 and A104 are shown, along with $\mathrm{H} 107$, which is a cluster ligand in the wild type protein [122, 125].

Fig. 9. Characterisation of [4Fe-4S] NsrR. (a) UV-visible absorption spectrum of NsrR showing the characteristic form of a [4Fe-4S] cluster [58]. (b) NRVS spectrum of [4Fe-4S] NsrR. The upper plot shows the ${ }^{57} \mathrm{Fe}$ PVDOS for unlabeled ( ${ }^{32} \mathrm{~S}$, blue line) and ${ }^{34} \mathrm{~S}$ (red line) labeled cluster. The lower plot shows a magnified view of the $200-450 \mathrm{~cm}^{-1}$ region demonstrating the isotope shifts due to the cluster sulfide substitution [47]. (c) Mössbauer spectrum of [4Fe-4S] NsrR enriched with ${ }^{57} \mathrm{Fe}$. The data are consistent with the presence of two quadrupole doublets with paramaters typical for a $[4 \mathrm{Fe}-4 \mathrm{~S}]^{2+}$ cluster $\left(\delta_{1}=0.442 \mathrm{~mm} \mathrm{~s}\right.$ ${ }^{1}, \Delta \mathrm{E}_{\mathrm{Q} 1}=1.031 \mathrm{~mm} \mathrm{~s}^{-1} ; \delta_{2}=0.481 \mathrm{~mm} \mathrm{~s}^{-1}, \Delta \mathrm{E}_{\mathrm{Q} 2}=1.309 \mathrm{~mm} \mathrm{~s}^{-1}$ [58]. (d) Positive ion mode ESITOF deconvoluted mass spectrum of [4Fe-4S] NsrR under non-denaturing conditions where the cluster bound form of the protein survives ionization and is detected [58]. (e) Resonance Raman spectrum of [4Fe-4S] NsrR with excitation at $488 \mathrm{~nm}$ and temperature $21 \mathrm{~K}$. The position of the intense feature at $343 \mathrm{~cm}^{-1}$ is characteristic of a [4Fe-4S] cluster with three Cys and one oxygenic ligand [58]. Parts (a), (c), (d) and (e) are reproduced from ref. [58], while part (b) is from ref. [47].

Fig. 10. Characterisation of the reaction of [4Fe-4S] NsrR with NO. (a) Absorbance spectra of [4Fe-4S] NsrR following sequential additions of NO up to a [NO]:[FeS] ratio of 10.5 (black lines show spectra recorded at ratios of $0,2.1,6.3$ and 10.5) revealing formation of iron-nitrosyl species [68]. (b) Mössbauer spectrum of NsrR enriched with ${ }^{57} \mathrm{Fe}$ following addition of excess NO. The data are consistent with the presence of two quadrupole doublets with paramaters typical of iron-nitrosyl species $\left(\delta_{1}=0.163 \mathrm{~mm} \mathrm{~s}^{-1}, \Delta \mathrm{E}_{\mathrm{Q} 1}=0.718 \mathrm{~mm} \mathrm{~s}^{-1} ; \delta_{2}=0.181 \mathrm{~mm} \mathrm{~s}^{-1}, \Delta \mathrm{E}_{\mathrm{Q} 2}\right.$ $=0.887 \mathrm{~mm} \mathrm{~s}^{-1}$ [47]. (c) $77 \mathrm{~K} \mathrm{EPR} \mathrm{spectra} \mathrm{of} \mathrm{[4Fe-4S]} \mathrm{NsrR} \mathrm{before} \mathrm{and} \mathrm{following} \mathrm{the} \mathrm{addition}$ of $11 \mathrm{NO}$ per cluster. g-values are indicated [68]. (d) CD spectra obtained during a titration equivalent to that in (a). Black lines show spectra recorded at [NO]:[FeS] ratios of 0 and 2.2 in 
$C$, and 2.2 and 6.2. Arrows indicate the direction of intensity changes. (e) Normalised absorbance $\left(\mathrm{A}_{360 \mathrm{~nm}}-\mathrm{A}_{420 \mathrm{~nm}}\right.$, green circles) and circular dichroism $\left(\mathrm{CD}_{430 \mathrm{~nm}}\right.$, black triangles; and $\mathrm{CD}_{330} \mathrm{~nm}$, blue squares) plotted versus the [NO]:[Fe-S] ratio [68]. (f) NRVS analysis of nitrosylated [4Fe-4S] NsrR. Spectra in the Fe-S $\left(0-450 \mathrm{~cm}^{-1}\right)$ and Fe-N $\left(450-750 \mathrm{~cm}^{-1}\right)$ regions are shown following addition of excess $\mathrm{NO}$ to ${ }^{32} \mathrm{~S} /{ }^{14} \mathrm{NO},{ }^{34} \mathrm{~S} /{ }^{14} \mathrm{NO}$ and ${ }^{32} \mathrm{~S} /{ }^{15} \mathrm{NO}$ labeled $[4 \mathrm{Fe}-$ 4S] NsrR, as indicated. Clear ${ }^{15} \mathrm{~N} /{ }^{14} \mathrm{~N}$ shifts are observed in the Fe-N region but ${ }^{34} \mathrm{~S} /{ }^{32} \mathrm{~S}$ shifts are not observed in the Fe-S region [47]. (g) Stopped-flow measurement of absorbance at $420 \mathrm{~nm}$ following addition of excess $\mathrm{NO}$ to [4Fe-4S] NsrR. The first few hundreds of milliseconds are shown in the inset. Multiple phases are observed over a short timescale and the data are fitted by a sequential binding model (black line) [68]. Parts (a), (c), (d) and (g) are reproduced from ref. [68], while parts (b) and (f) are from ref. [47].

Fig. 11. NsrR regulatory system. Scheme summarizing the mechanism of $S$. coelicolor NsrR NO-sensing and regulation. Specific DNA binding for ScNsrR has been reported for [4Fe-4S] NsrR, which acts as repressor of $h m p A$ genes encoding NO-detoxifying enzymes. Nitrosylation of the cluster relieves NsrR mediated repression, allowing transcription of $h m p$. Recent data showed that, for the hmpA2 promoter, only $2 \mathrm{NO}$ per cluster was required to abolish DNA binding [68]. Note that a high resolution structure of NsrR is not yet available, and the schematic representation included here is based on available structures of the Rrf2 proteins CymR and IscR [122, 125].

Fig. 12. Crystal structure of FNR. (a) Aliivibrio fischeri FNR is a homo-dimer, composed of momomeric subunits (purple and blue, respectively). Each subunit contains an $\mathrm{N}$-terminal sensory domain that binds an all cysteine ligated [4Fe-4S] cluster (shown as space filled), a C-terminal DNA binding domain and large dimerization helix. (b) The [4Fe-4S] cluster binding loop of AfFNR. The location of cluster ligands (Cys20, 23, 29, 122) are as indicated (PBD: 5E44) [133].

Fig. 13. Crystal structure of SoxR. (a) Annotated structure of the SoxR (PDB: 2ZHG) monomer containing a C-terminal [2Fe-2S] cluster (shown as space filled). Inset; Surface view of cluster binding domain highlighting the solvent exposed nature of the cluster. (b) Structure of SoxR bound to soxS promoter DNA [191].

Fig. 14. SoxR regulatory system. Scheme summarizing the mechanism of the E. coli SoxRS system. Specific DNA binding of [2Fe-2S] SoxR has been reported in both the reduced and oxidized states. The cluster is maintained in the reduced state, $[2 \mathrm{Fe}-2 \mathrm{~S}]^{1+}$, by the $r s x$ system at the expense of NADPH. Oxidation of the cluster to the $[2 \mathrm{Fe}-2 \mathrm{~S}]^{2+}$ state, through direct interaction of redox cycling drugs (or perturbations to the NADPH/NADP pool), activates the transcription of soxS, which in turn activates transcription of the soxS operon (e.g. $\operatorname{sodA}$ ). Note that a high resolution structure of soxS is not yet available; the schematic representation included here is based on the published structure of the AraC/XylS family protein Rob [226], which shares homology with SoxS. Non-enteric bacteria (e.g. S. coelicolor) do not contain SoxS, and so SoxR itself directly regulates the sox regulon.

Fig. 15. Crystal structure of anaerobic Hcp. (a) Hcp from D. vulgaris (PDB: 1W9M) contains two types of Fe-S cluster (shown as space filled). The first is the so-called variable cluster, which is present as either a [4Fe-4S] $(D$. vulgaris) or [2Fe-2S] $(E$. coli) cluster $[221,227]$. The second is the so-called hybrid cluster, $\left[\mathrm{Fe}_{4} \mathrm{O}_{3} \mathrm{~S}_{2}\right]$, which is the main feature of the $\mathrm{Hcp}$ structure. (b) Fine detail of the catalytic hybrid cluster (from PDB: 1E1D) showing ligand arrangement, oxygen atoms and cysteine persulfide (on C406). The hybrid cluster catalyzes the reduction of $\mathrm{NO}$ to nitrous oxide $\mathrm{N}_{2} \mathrm{O}$ [148]. 